\title{
Microstructured Reactors for Multiphase Reactions: State of the Art
}

\author{
Madhvanand N. Kashid and Lioubov Kiwi-Minsker* \\ Group of Catalytic Reaction Engineering (GGRC), Ecole Polytechnique Fédérale de Lausanne (EPFL), \\ EPFL-SB-ISIC-GGRC, station 6, CH-1015 Lausanne, Switzerland
}

The manufacture of chemicals in microstructured reactors (MSR) has become recently a new branch of chemical reaction engineering focusing on process intensification and safety. MSR have an equivalent hydraulic diameter up to a few hundreds of micrometers and, therefore, provide high mass- and heat-transfer efficiency increasing the reactor performance drastically, compared to the conventional one. This article provides a comprehensive overview of the state of the art of the MSR applied for multiphase reactions. The reactions are classified based on the number of phases involved: fluid-fluid, fluid-solid, and three phase reactions. In the first part of the review, limitations of conventional reactors are discussed in brief. Furthermore, different types of MSR and their advantages with respect to their conventional counterparts are described. Particular attention is given to the identification of the parameters that control the flow pattern formed in microcapillaries regarding the mass-transfer efficiency. Case studies of various multiphase reactions carried out in MSR are discussed in detail.

\section{Introduction}

Industrial reactions involving more than one phase have become rather a rule than exception. Multiphase reactions are divided into three groups based on the number of phases involved: fluid-fluid, fluid-solid, and three phase reactions. The classification can further be made based on the presence of a catalyst such as catalytic and noncatalytic reactions. Two types of catalysts are used: homogeneous (catalyst is in the same phase as the reactants) and heterogeneous (generally solid) catalyst. Typical application areas include the manufacture of petroleum-based products and fuels, production of commodity and specialty chemicals, pharmaceuticals, polymers, herbicides and pesticides, refining of ores, and pollution abatement. ${ }^{1}$ The reactors used for such reactions are called as multiphase reactors.

When selecting a multiphase reactor, various parameters must be considered such as the number of phases involved, the differences in the physical properties of the participating phases, the inherent reaction nature (stoichiometry of reactants, intrinsic reaction rate, isothermal/adiabatic conditions, etc.), the postreaction separation, the residence time required, and the massand heat-transfer characteristics of the reactor. For a given reaction system, the first four aspects are usually controlled to only a limited extent, if at all, while the remainders serve as design variables to optimize reactor performance. High rates of heat and mass transfer improve effective rates and selectivities and the elimination of transport resistances, in particular for the rapid catalytic reactions, enable the reaction to achieve its "chemical" potential in the optimal temperature and concentration window. Transport processes can be ameliorated by higher heat and mass exchange which in turn depends upon higher interfacial surface areas and short diffusion paths. These are easily attained in microstructured reactors (MSR). MSR contain open paths for fluids with diameter in the submillimeter range. The research field which deals with such reactors is often referred as "microreactor" or "microreaction" technology.

Microreactor technology is one of the powerful techniques of process intensification (PI). The concept of PI was pioneered by Professor Ramshaw and his group at Imperial Chemical

* To whom correspondence should be addressed. E-mail: lioubov.kiwi-minsker@epfl.ch.
Industries (ICI), UK, in the late 1970s, who considered how one might reduce equipment size by several orders of magnitude. However, in recent years, the objective of process intensification is broadening and different techniques are being exploited such as dynamic operation of conventional reactors, ${ }^{2,3}$ special reaction media, the use of nonconventional energy sources, etc. More attention has been paid on microreactor technology due to its advantages such as reduced cost (smaller equipment, reduced piping, low energy, increased reactivity, higher yields/selectivities, reduced waste, etc.), enhanced safety (low hold-up and controlled reaction conditions), compact size of the plant (much higher production capacity and/or number of products per unit of manufacturing area), and reduced plant erection and commissioning time (time to market).

Over the last two decades, multiphase MSR have been used in the laboratory as well as in industries. Some of the industries/ institutes and their activities in the field of microreaction technology are listed in Table 1. Such activities are regularly reviewed through various scientific meetings and conferences. One of the most important conferences, IMRET (International Conference on Microreaction Technology), was started in 1997 (Frankfurt, Germany) and successfully followed by 10 meetings. The information on this research area is available in the form of books. ${ }^{27-29}$ In addition to usual update through the scientific journal papers, few reviews are also published on reactions in MSR. ${ }^{24,25,30-34}$ Recently, a three volume handbook on microreactors, edited by Hessel et al., ${ }^{35}$ has appeared.

The aim of this review is to provide brief information on the state-of-the art and future perspectives of the multiphase MSR based on the case studies reported in the literature. The first part of the review deals with limitations of the conventional reactors. Different types of multiphase MSR with their advantages over conventional reactors are presented afterward. Particular attention is given to the identification of the parameters that control the flow pattern formed in MSR like slug and parallel flow, and discussed their mass-transfer efficiency. Then, the examples of different gas-liquid reactions in MSR are given in detail. The liquid-liquid reactions are further presented and classified into different types such as laboratory analysis reactions, synthesis, enzymatic reactions, phase transfer catalysis, and polymerization. The three phase reactions are also described. 
Table 1. MSR Activities in Selected Industries/Institutes

\begin{tabular}{|c|c|}
\hline MSR activities & company/institute \\
\hline MSR/mixer design and fabrication, process development & $\begin{array}{l}\text { IMM Mainz, }{ }^{4,5} \text { Forschungszentrum Karlsruhe } \mathrm{GmbH},{ }^{6} \text { Ehrfeld } \\
\text { Mikrotechnik BTS, }{ }^{7} \text { Microinnova Engineering } \mathrm{GmbH}^{8}\end{array}$ \\
\hline MSR design and fabrication, development of laboratory systems & $\begin{array}{l}\text { Mikroglas GmbH, }{ }^{9} \text { Mikronit microfluidics, }{ }^{10} \text { Little Things Factory, }{ }^{11} \\
\text { Syrris } 12\end{array}$ \\
\hline Engineering services of MSR & Bayer Technology Services, ${ }^{13}$ Alfa Laval ${ }^{14}$ \\
\hline Development of MSR materials & Corning ${ }^{15,16}$ \\
\hline MSR process development and demonstration of industrial production & $\begin{array}{l}\text { Merck, }{ }^{17} \text { SK Chemicals, }{ }^{18} \text { Ampac Fine Chemicals, }{ }^{19} \text { Phoenix } \\
\text { Chemicals, }{ }^{20} \text { Clariant GmbH, }{ }^{21} \text { DSM, }{ }^{16,22,23} \text { Lonza }^{24,25} \\
\text { Sigma-Aldrich }\end{array}$ \\
\hline
\end{tabular}

The last part of the review sums up the benefits of the MSR and perspectives for further research in this area.

\section{Conventional Multiphase Reactors}

Multiphase reactors can be divided into two types: fluid-fluid reactors (gas-liquid, liquid-liquid) and three phase reactors (gas-liquid-solid). In gas-liquid systems, the reactant diffuses into the liquid phase where the reaction takes place. In liquid-liquid systems, it is possible that the reaction takes place in both the phases (e.g., oximation of cyclohexanone ${ }^{36}$ ). The limitations to the reactor performance are based on the rate of the reaction. If the reaction is fast, the mass transfer should be relatively high in order to overcome mass transfer limitations. Some reactions are limited by mass transfer due to the very low specific interfacial area attained in the conventional reactor since the surface to volume ratio is in the order of few squared meters per cubic meter. The enhancement of specific interfacial area can increase the overall performance of the reactor. Conventionally, the fluid-fluid reactions are carried out using agitated (mechanical, ${ }^{37}$ bubble $^{38}$ ), centrifugal, ${ }^{39,40}$ column (packed, ${ }^{41,42}$ plate, ${ }^{43,44}$ vibrating plates ${ }^{45}$ buss loop ${ }^{46,47}$ etc.), tubular $\left(\right.$ straight, ${ }^{48}$ coiled $^{49}$ ), and film reactors ${ }^{50}$ as shown in Figure 1. The contacting principles are bubbling, filming or spraying of one fluid into the other. For gas-liquid-liquid reactions, similar equipments are used.

The advantages and limitations of fluid-fluid reactors are listed in Table 2. An agitated reactor is usually followed by a gravity settling shallow basin called as settler where the liquids separate for discharge. In a centrifugal reactor, two phases of different densities are fed to an agitated tank and are rapidly mixed in the annular space between the rotor and the stationary housing. The high pressure feed and its intense mixing in the annular space alters the specific gravities of fluids. The physical separation efficiency is very high as compared to the mixersettler, and therefore, it is generally used for the system with narrow density difference (liquid-liquid systems). The third variety of equipment, the columns, is commonly used in chemical industries in their countercurrent mode of operations. Tubular contactors offer a number of advantages because of their flexibility, simplicity, and wide range of operating window. To intensify the mixing in the tubular reactor, internals like static mixers are useful. Such equipment was used for mixing immiscible liquids in a compact configuration and is found to be effective (e.g., transesterification reactions of canola oil and methanol ${ }^{51}$ ). In falling film contactors, a thin film is created by a liquid falling under gravity pull. The liquid flows over a solid support, which is normally a thin wall or a stack of pipes. In conventional falling film devices, a film with a thickness of $0.5-3 \mathrm{~mm}$ is generated. ${ }^{33}$ The film flow becomes unstable at high throughput and the film may break up into rivulets, fingers, or a series of droplets at high flow rates. Besides the limitations mentioned in the Table 2, a common drawback of all abovementioned equipment is the inability to condition the drop or film size precisely and to avoid the nonuniformities that arise due to the complex hydrodynamics. This leads to uncertainties in the design and often imposes severe limitations on the optimal performance.

The fluid-solid reactions are being carried out using different types of reactors such as packed bed reactor, fluidized bed reactor, and slurry reactor (Figure 2). The advantages and limitations of these reactors are listed in Table 3. Among all, packed bed reactors are relatively simple, easy to operate, and more suitable for the reactions which require relatively high amount of catalyst as it can accommodate $60-65 \%$ of the catalyst. The relatively higher residence time in the reactor makes it more suitable for slow reactions (for examples see AlDahhan et al. ${ }^{52}$ ). However, heat addition or removal and liquid maldistribution are two common problems observed in this type of reactor. The suppression of hot spot formation in an exothermic reaction is one of the challenging tasks while designing such reactors. Several attempts have been made to overcome this problem, and notably, desorptive cooling was used by Grünewald and Agar. ${ }^{53}$ Fluidized bed gives relatively higher performance for gas-solid reactions, but within a narrow operating window. Another type of reactors, slurry reactor, effectively utilizes the catalyst. However, catalyst separation is difficult and a filtration step is required to separate fine particles from the product. Moreover, when applied in the continuous mode, back mixing usually lowers selectivity. ${ }^{54}$

Gas-liquid reactions catalyzed by solids represent a very important class of reactions. They may be carried out in either slurry (such as bubble column, stirred tank, and gas-liquid

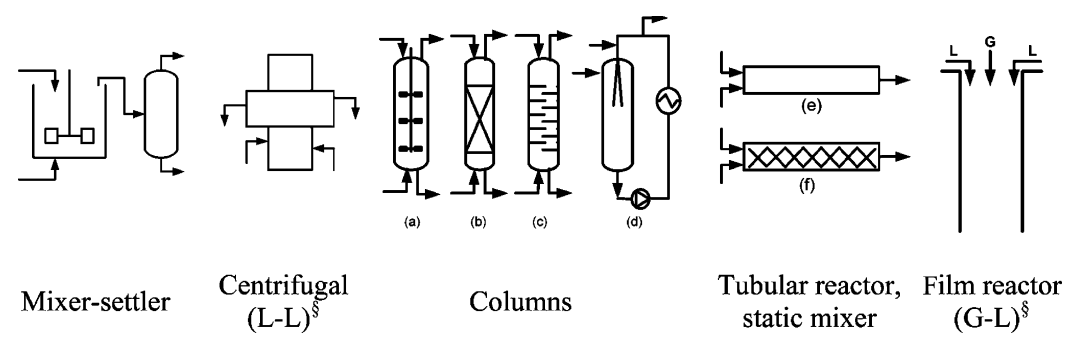

Figure 1. Conventional reactors used for fluid-fluid reactions: (a) multistage agitated column, (b) packed column, (c) sieve tray column, (d) buss loop reactor, (e) tubular reactor, (f) static mixer. $\S$ denotes $\mathrm{G}=$ gas, $\mathrm{L}=$ liquid. 
Table 2. Different Types of Fluid-Fluid Reactors with Their Advantages and Limitations

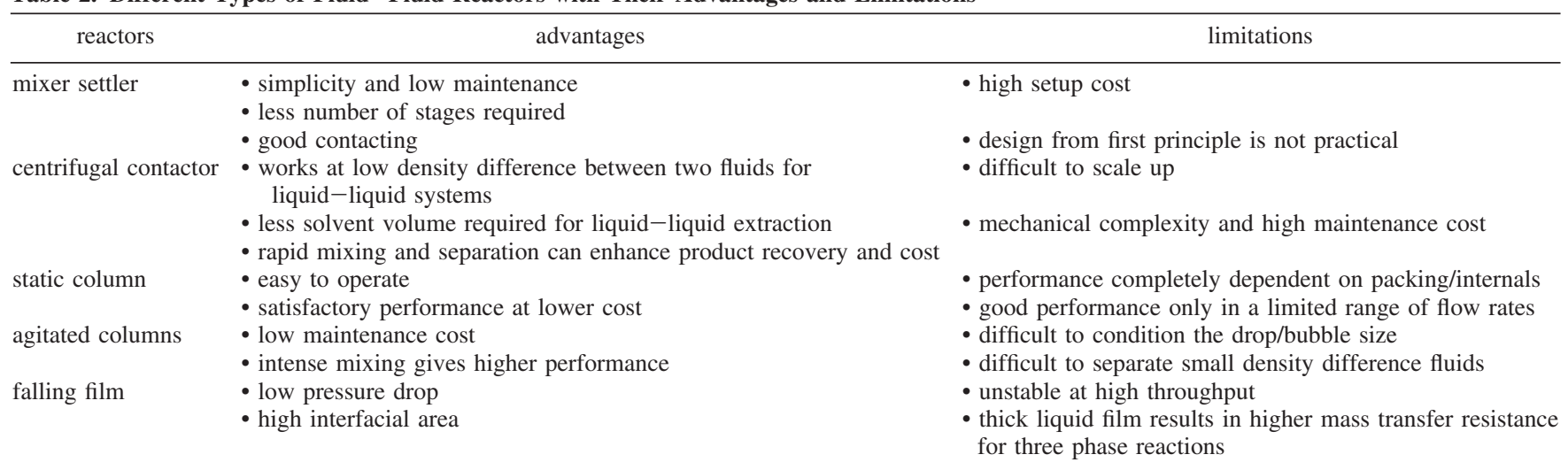

Table 3. Different Types of Fluid-Solid Reactors with Their Advantages and Limitations

\begin{tabular}{|c|c|c|}
\hline reactors & advantages & limitations \\
\hline packed bed reactor & $\begin{array}{l}\text { - easy to operate } \\
\text { - can accommodate } 60-65 \% \text { (volumetric) catalyst } \\
\text { - suitable for slow reactions }\end{array}$ & $\begin{array}{l}\text { - flow maldistribution } \\
\text { - higher pressure drop } \\
\text { - possibilities of hot spot formation }\end{array}$ \\
\hline fluidized bed reactor & - better heat transfer & $\begin{array}{l}\text { - good performance in the limited range of flow rates } \\
\text { - complex hydrodynamics }\end{array}$ \\
\hline slurry reactor & $\begin{array}{l}\text { - effective utilization of catalyst } \\
\text { - good liquid-solid mass transfer } \\
\text { - good heat transfer }\end{array}$ & $\begin{array}{l}\text { - moderate gas-liquid mass transfer } \\
\text { - catalyst separation is difficult and a filtration step is required } \\
\text { - low selectivity in continuous mode due to back mixing }\end{array}$ \\
\hline
\end{tabular}

fluidized configurations) or fixed-bed reactors (trickle bed with cocurrent downflow or cocurrent upflow, segmented bed, and countercurrent gas-liquid arrangements). The hydrodynamics in three phase reactors are extremely complex due to the three phases and their convoluted interactions. An example is the grazing behavior of small solid particles enhancing mass transfer at gas-liquid interfaces. The scale-up from laboratory to the production scale thus poses numerous problems with respect to the reactant mixing, temperature control (heat removal), and catalyst performance, ${ }^{55}$ being solved analytically to only a limited extent for reactors with well-defined flow patterns.

\section{Microstructured Reactors (MSR)}

Unlike conventional reactors, most MSR are at the research stage, but a few have been made available commercially. Therefore there is not enough information to categorize the reactors based on the type of reaction. However, MSR should be used to envisage the case-specific drawbacks in conventional processing options such as severe transport limitations (heat or mass transfer), low yields, and high wastage due to multistep reactions, high dilutions with inerts or solvents for safety, poor control of reaction parameters, and failure to meet market quality demand. A detailed reactor description and studied reaction in MSR presented in the subsequent sections will elaborate the reactor choice.

3.1. Multifluid Reactors. Multifluid MSR consist of gasliquid, liquid-liquid, and gas-liquid-liquid reactors. Multiphase MSR generally take advantage of the large interfacial area, fast mixing, and reduced transfer limitations. They provide

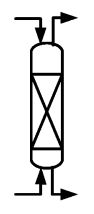

Packed bed

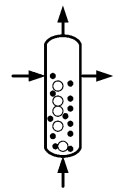

Fluidized bed reactor

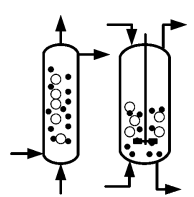

Slurry reactor (bubble and agitated)

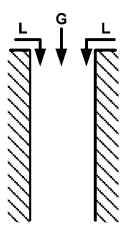

Film reactor (catalytic wall)
Figure 2. Conventional reactors used for fluid-solid reactions. an enhanced performance relative to conventional benchscale systems due to diminished diffusion times and increased mass transfer across phase boundaries. Another benefit comes from the reduced dispersion when immiscible fluids are forming alternative succession of segments. This flow pattern is referred as slug or segmented flow and can be produced with great regularity for gas-liquid or immiscible liquids systems. The classification of MSR with respect to the basic contacting principles for fluid-fluid systems is depicted in Figure 3. Fluid-fluid MSR can be subdivided into two types: micromixers and microchannels.

3.1.1. Micromixers. Three types of mixers are available: mixer-settler, cyclone, and interdigital mixer (see Figure 3). The principle of fluid contacting in a micromixer-settler is almost similar to the conventional mixer-settler assembly. However, due to reduced size of the equipment the moving part of the mixer is replaced by a static part. Two fluid streams, generally liquid-liquid, that are introduced from the top of the mixer and a biphasic mixture are taken out from the top central line and transfered to the minisettler where the phases disengage based on their density difference. ${ }^{56}$ The advantage of mixersettler over channel reactors is that the drop size and specific interfacial area can be changed over a wide range in a given reactor. With increase in the inlet flow velocity, the drop size decreases and thus specific interfacial area increases. The maximum values of specific interfacial area are reached within less than $1 \mathrm{~s}$, being up to 5 -fold higher than other MSR ${ }^{27}$ It is also possible to use arrays of multiple static elements in the mixer to extend the throughput. Thus, it gives desired performance and allows higher throughput due to the larger pipe diameters though the small size of the droplets. However, similar to conventional contactor it is difficult to control the drop size in the reactor and thus the interfacial area.

In the cyclone mixer (Figure 3b), two phases are dosed through two different nozzles. The bubble size can be influenced by the arrangement of gas and liquid injection nozzles (either parallel or vertical). ${ }^{31}$ The spiral patterns of the gas bubbles similar to cyclone vortex are formed in the liquid. Another type of mixer, interdigital mixer, induces the gas and liquid streams 


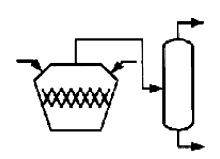

(a)

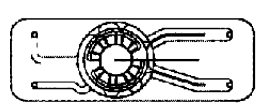

(b)

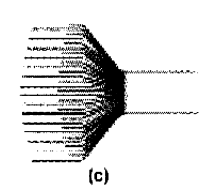

Micromixer

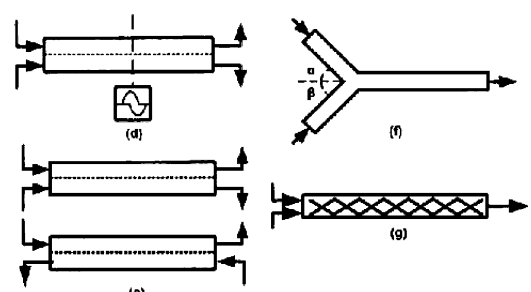

(e)

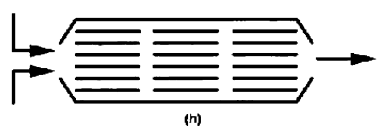

(h)

Microchannels

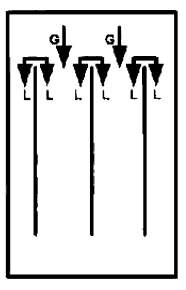

Microstructured film reactor (gas-liquid)

Figure 3. Schematic representation of fluid-fluid microstructured reactors: (a) micromixer settler, (b) cyclone mixer, (c) interdigital mixer, (d) microchannel with partial overlap, (e) microchannel with membrane or metal contactor, (f) microchannels with inlet $\mathrm{Y}$ or $\mathrm{T}$ shaped contactor, (g) microchannel with static internals, (h) parallel microchannels with internal redispersion units.

to merge with or without prior splitting of the gas and liquid streams into finer substreams. The reaction channel downstream of the mixing section is of sufficiently large diameter so that the small bubbles generated in the mixing section pack together in the reaction channel resulting in foam flows. ${ }^{33}$

3.1.2. Microchannels. Another type of MSR, microchannels, can be divided into various types such as microchannels with partial overlapping (Figure 3d), microchannels with mesh contactors (Figure 3e) (porous membrane, sievelike structure, etc.), microchannels with inlet $\mathrm{Y}$ or $\mathrm{T}$ shaped contactor (Figure 3f), microchannels with a static mixer (Figure $3 \mathrm{~g}$ ), micropacked bed reactor, and multichannel contactors with intermediate redispersion units (Figure $3 \mathrm{~h}$ ). The contacting principle of fluids in all microchannels is similar for both gas-liquid and liquid-liquid systems.

Microchannels with Partial Two Fluid Contact (Figure 3d). In this type of channel, anodically bonded silicon/glass plates each carrying a single channel with rectangular and semicircular cross section are fitted in order to form partially overlapping channels (see Figure 3d). The advantage of this reactor is that the contact between two fluids can be adjusted depending on the application. Partially overlapping channels MSR were developed for liquid-liquid extraction by Central Research Laboratory (CRL), UK ${ }^{57}$ The concept was tested for large throughput and 120 identical contactors were operated in parallel in one device. ${ }^{58}$ Out of this work, a platform for the use of MSR for liquid-liquid extraction was created.

Microchannels with Mesh or Sievelike Interfacial Support Contactors (Figure 3e). Similar to partially overlapping channels, microchannels with mesh contactors (Figure $3 \mathrm{e}$ ) are used to create the partial contact of fluids. The advantage of these contactors is that both modes of operation, cocurrent and countercurrent, can be applied. Besides, the flow is stabilized because of the solid support between two fluids. The solid contactors are porous membrane $\mathrm{e}^{59,60}$ and metal sheets with sieve like structure. ${ }^{61}$ Similar to parallel flow, the mass transfer in both cases is only by diffusion and the flow is under laminar flow regime dominated by capillary forces. The membrane contactor shows an advantage that it is flexible with respect to the ratio of two fluids. In addition to flow velocities, the mass transfer is a function of membrane porosity and thickness. In other type of microextractor, two microchannels are separated by a sievelike wall architecture to achieve the separation of two continuous phases. However, the hydrodynamics in both types of contactors is more complex due to interfacial support and

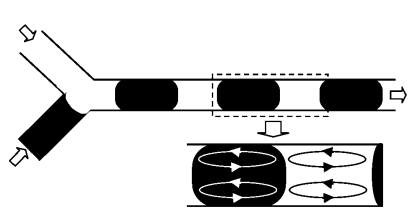

(a)

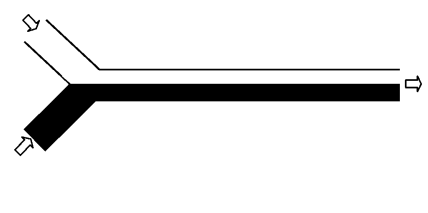

(b)
Figure 4. Stable flow patterns that can be achieved in the liquid-liquid flow capillary microreactor: (a) slug flow, (b) stratified (parallel) flow.

bursting of fluid from one channel to the other at a higher pressure drop in the case of countercurrent flow limits their applications.

Microchannels with Inlet $\mathbf{T}$ and $\mathbf{Y}$ type Contactor (Figure 3f). In this case, the mixing is restricted to only uniting the fluid streams using T or Y types of junctions. Depending on the flow mixer geometry, physical properties of fluids, and operating conditions, different flow regimes are observed. For both types of systems, the most stable flow regimes observed are slug flow (or Taylor, segmented flow) and parallel flow (or annular in gas-liquid depending on inlet geometry) as shown in Figure 4. The difference between two flow regimes is listed in Table 4. As can be seen, slug flow shows added advantages over parallel flow, and therefore, the former is widely used compared to the latter. The establishment of stable flow pattern is very important and is quantified using capillary number (viscous stresses relative to interfacial tension) which is defined as

$$
C a=\frac{u \mu}{\gamma}
$$

where $u, \mu$, and $\gamma$ are the flow velocity, dynamic viscosity, and interfacial tension, respectively. In a gas-liquid system, Taylor flow appears at low gas velocities and parallel flow appears at high gas velocities, i.e. at high inertia. At low capillary numbers $(\mathrm{C} a<0.01)$, interfacial forces dominate shear stresses and the dynamics of breakup are dominated by pressure drop across the emerging droplet. ${ }^{62,63}$ The shear stress exerted on the interface of the emerging bubble is not sufficient to distort it significantly, and the bubble blocks almost the entire cross section which increases the pressure upstream of the emerging bubble and leads to squeezing of the neck of the immiscible threads. The process of breakup is independent of $\mathrm{Ca}$, and the length of the bubble can be obtained by ${ }^{63}$

$$
\frac{L}{W}=1+a \frac{Q_{\mathrm{d}}}{Q_{\mathrm{c}}}
$$


- slug flow is a flow of series of slugs (plugs) of one phase separated by the other.

- each slug serves as an individual processing subvolume. Generally, one phase acts as continuous while other discrete

- mass transport is due to convection within each slug and diffusion between two adjacent slugs

- relatively higher interfacial area which can be changed in a given reactor by varying the flow rates

- intensity of internal circulations increases with flow and thus diffusive penetration between two phases

- downstream separation is difficult

where $L$ and $W$ are the bubble length and microchannel width while $Q_{\mathrm{d}}$ and $Q_{\mathrm{c}}$ are the volumetric flow rates of gas and liquid phase, respectively. The constant, $a$, has a value of order 1 .

In liquid-liquid systems, the interpenetration of two streams in the vicinity of the junction generates the characteristic alternating slug flow structure. Tice et al. ${ }^{64}$ investigated the formation of slugs in liquid-liquid flow for two cases in T type reactors where the continuous phase flows in the straight channel while the dispersed phase is introduced through a side channel: nonviscous (viscosity of $2.0 \mathrm{mPa} \mathrm{s}$ ) and viscous (viscosity of $18 \mathrm{mPa}$ s) aqueous solutions. In both cases, the flows form slugs up to a certain threshold velocity, which decreases with increase in the viscosity of liquids. The Reynolds number was low $(R e<$ 1 ), and at these values, $R e$ has a negligible effect on the formation of slugs and mixing inside them. ${ }^{65}$ The threshold velocity was quantified based on the dispersed phase volume fraction and $\mathrm{Ca}$. The results show that slugs formed reliably in a flow of waterimmiscible carrier fluid for $\mathrm{C} a<0.01$, although plugs were able to form at higher $\mathrm{Ca}$ at lower ratios of the aqueous phase flow rate to the flow rate of the carrier fluid for $\mathrm{R} e<1$.

Wetting in liquid-liquid slug flow is an unresolved issue. If the surface tension between one of the liquid phases and the wall material is higher than the interfacial tension between two liquids, this liquid forms enclosed slugs. The other liquid corresponds to the continuous phase forming a thin wall film of a few micrometers. If the flow does not satisfy these conditions both liquids flow alternatively. With further modification in the wall surface properties, especially for rectangular channel, the parallel flow is achieved utilizing the wall adhesion effect. ${ }^{66}$

Microchannels with Static Mixers (Figure 3g). In this case, mixing is either achieved by uniting, dividing, and recombining fluid streams or using static internals in the microchannels (Figure 3g). Köhler et al. ${ }^{67}$ explained the concept of digital reaction technology which is an introduction of a digitalization principle by the use of a large number of small reaction volumes handled serially in a flow channel. Different $\mathrm{T}$ and $\mathrm{Y}$ type mixers can be used to split the flow stream into two equal flow streams of biphasic mixture and change the size of the drops. Additionally, by changing the diameter of the channel and creating resistance to the flow, multiple drops can be united and the interfacial area can be decreased. IMM developed a caterpillar micromixer which consists of a ramplike structure where the fluid moved constantly up and down and the mixing is achieved by a sequence of repeated splitting-reshaping-recombination processes. ${ }^{27}$ Sometimes foam stacks are also used as static mixer for dispersing two immiscible phases.

Parallel Microchannels with Internal Redispersion Units (Figure 3h). In this case, the redispersion units are placed along the length of the parallel microchannels and are made of a metal sheet having multiple channels or with metal foam. The aim is to continuously provide large surface area by repetitive formation and breaking of the drops. ${ }^{68}$

\author{
- parallel flow is a flow of two parallel streams \\ - both phases are continuous \\ - mass transfer is due to diffusion only \\ - relatively low interfacial area and is constant in given microreactor \\ - no effect of flow velocity on diffusive penetration \\ - downstream separation is relatively easy
}

3.1.3. Falling Film Reactor for Gas-Liquid Reactions. Falling film microreactor is one of the most commonly used MSR for gas-liquid reactions (examples are given in gas-liquid reactions section). The liquid flows downward due to gravity in the form of a film and the gas flows through the open space which lies in the top cover of the housing. The film thickness is about $15 \mu \mathrm{m}$ over the reaction plate which corresponds to a specific interfacial area of up to $20000 \mathrm{~m}^{2} \mathrm{~m}^{-3}$, being few orders of magnitude higher than that of the most known commercial systems as bubble columns $\left(50-600 \mathrm{~m}^{2} \mathrm{~m}^{-3}\right)$ and impinging jets $\left(90-2050 \mathrm{~m}^{2} \mathrm{~m}^{-3}\right){ }^{31}$ The microchannels on the reaction plate can have width from 100 up to $1200 \mu \mathrm{m}$, depths from 100 up to $600 \mu \mathrm{m}$, and the length varies depending on the residence time. The bottom housing section of the falling film reactor consists of a heat exchanger.

3.2. Fluid-Solid Reactors. The difference between the gas-liquid and gas-liquid-solid systems is that the solid phase is a catalyst where reaction takes place. Different types of gas-liquid-solid MSR have been developed (Figure 5), using different gas-liquid contacting principles. ${ }^{33}$ These principles can be classified as follows:

- Continuous-phase contacting, where the fluid phases are separated. Examples are microstructured falling film and mesh reactors.

- Dispersed-phase contacting, obtained when one of the fluid phases is dispersed into the other phase. Examples are microbubble columns and micropacked-bed reactors.

3.2.1. Continuous Phase Contacting. In conventional falling film devices, the film thickness is big (up to $\sim 3 \mathrm{~mm}$ ) which results in an important mass transfer resistance for the gaseous reactant diffusing to the solid catalyst on the reactor wall. In addition, the film flow becomes unstable at high throughput and the film may break up into rivulets, fingers, or a series of droplets. These problems can be overcome by microstructuring the solid wall. ${ }^{69}$ The dimensions of the falling film reactor are mentioned in the previous section.

The main drawback of the microstructured falling film reactor is the short residence time of the liquid in the channels, which is in the range 5-20 s, depending on the physical properties of the liquid and the operating conditions. The residence time can be increased by prolonging the channels or by decreasing the angle of descent, which can be achieved with a helical microchannel falling film reactor. For a microchannel with a
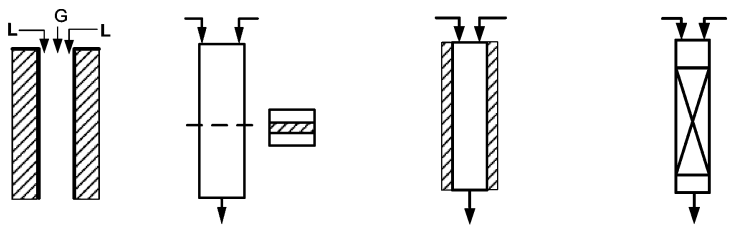

Falling film reactor Mesh reactor Catalytic wall reactor Packed bed reactor

Figure 5. Schematic presentation of fluid-fluid-solid reactors. 
small angle descent of $7.5^{\circ}$, the residence time could be increased by a factor of $\sim 50 .{ }^{70}$

In another continuous phase contacting MSR, a mesh reactor, the gas and liquid flow through separate channels. To provide stable operation, the fluid interface is immobilized by well-defined openings obtained with a thin mesh. ${ }^{71}$ Interfacial forces help to stabilize the fluid interface within the openings, while fluid layers are thin enough to enhance mass transfer. The meniscus shape at the interface between the two phases defines the available area for mass transfer and is a function of contact angle, pore geometry and pressure difference between phases. The open area of the micromesh contactor is about $20-25 \%$, which leads to a gas-liquid interfacial area of $2000 \mathrm{~m}^{2} \mathrm{~m}^{-3}$, well above the values obtained in traditional stirred tank reactors. This high gas-liquid interfacial area combined with the small fluid layer thickness resulted in high mass transfer coefficients.

3.2.2. Dispersed Phase Contacting. Microbubble reactors (microchannels with slug or bubble/drop flow) ${ }^{72}$ and micropacked-bed reactors ${ }^{73}$ come under the class of dispersed phase contacting. Regular flow patterns are provided by the segmented flow in a single capillary or in multichannel microreactors. In segmented flow gas-liquid-solid reactors, the liquid usually flows over the solid surface while the gas flows through the liquid in the central core.

Miniaturized packed-bed microreactors follow the paths of classical engineering by enabling trickle-bed or packed bubble column operation. The hydrodynamic characteristics of three phase reactors, such as pressure drop and residence time distribution, can be determined similar to those for fluid-solid and fluid-fluid reactors.

\section{Gas-Liquid Reactions}

Gas-liquid MSR are operated under the film flow or Taylor flow regime. In both cases, the film thickness is of particular importance. The investigation of hydrodynamics and mass transfer characteristics of gas-liquid MSR are given in the work of Kashid et al. ${ }^{74}$ Bercic and Pintar ${ }^{75}$ studied gas-liquid mass transfer for the absorption of methane in water using different capillaries and proposed the following correlation for volumetric mass transfer coefficient $\left(k_{\mathrm{L}} a\right)$ :

$$
k_{\mathrm{L}} a=\frac{0.111\left(u_{\mathrm{L}}+u_{\mathrm{G}}\right)^{1.19}}{\left[\left(1-\varepsilon_{\mathrm{G}}\right) L_{\mathrm{U}}\right]^{0.57}}
$$

where $u_{\mathrm{L}}, u_{\mathrm{G}}, \varepsilon_{\mathrm{G}}$, and $L_{\mathrm{U}}$ are the superficial velocity of liquid, gas, gas hold-up, and length of unit cell, respectively. Further, van Baten and Krishna ${ }^{76}$ developed a model for rising Taylor bubble flow in circular capillaries which takes into account the diameter of the capillary:

$$
k_{\mathrm{L}} a=4.5 \sqrt{\frac{D_{\mathrm{m}} u_{\mathrm{G}}}{L_{\mathrm{U}}}} \frac{1}{d_{\mathrm{t}}}
$$

where $D_{\mathrm{m}}$ and $d_{\mathrm{t}}$ are molecular diffusivity and diameter of the MSR, respectively. In Taylor flow regimes, the liquid usually exhibits good wettability for the channel wall, forming a thin wall film over which the gas bubbles glide. The wall film provides a lubricating action to the enclosed bubbles, and as a consequence, bubbles flow at relatively higher velocity than the liquid. Often the length of the bubble is many times greater than the channel diameter; the film surrounding the bubble becomes saturated with the absorbed component and becomes inactive. Pohorecki ${ }^{77}$ developed a criteria to avoid film saturation and investigated the effectiveness of the interfacial area for mass transfer in two phase flow in MSR:

$$
\frac{L_{\mathrm{b}} D_{\mathrm{m}}}{v_{\mathrm{b}} \delta_{\text {film }}^{2}} \ll 1
$$

where $L_{\mathrm{b}}, v_{\mathrm{b}}$, and $\delta_{\text {film }}$ are the length of the bubble, velocity of bubble, and film thickness, respectively.

In gas-liquid reactions in MSR much focus has been given to the halogenation in general and fluorination in particular. Besides, nitration, oxidation and sulfonation reactions have been studied using different types of MSR. All reactions and reactors used are listed in Table 5.

4.1. Halogenation. Fluorination has been carried out using conventional reactors as a multistep process (e.g., Schiemann reaction $^{69}$ ). MSR have been employed for this type of reactions where direct fluorination can reduce a significant number of steps in the synthesis of fluorinated compounds. The first application of MSR for selective fluorination was demonstrated by Chambers et al. ${ }^{78}$ using an annular flow regime in order to form a film of liquid over the solid material. Further, Jähnisch et al. ${ }^{69}$ carried out direct fluorination of toluene, pure or dissolved in either acetonitrile or methanol using elemental fluorine. Two types of reactor were employed: falling film microreactor and a microbubble column (Figure 6). The falling film MSR was oriented vertically and a thin liquid film is fed through orifices into the reaction channels (with $100 \times 300 \mu \mathrm{m}$ cross section) generating a relatively large surface for contact to the gas. In the microbubble column, the liquid and gaseous reactants are contacted through a static micromixer, and, subsequently, fed into the reaction channels. For reaction unit, two types of channels, narrow $(50 \times 50 \mu \mathrm{m})$ and wide $(300 \times 100 \mu \mathrm{m})$ were used. The specific interfacial area achieved in these channels was $27000 \mathrm{~m}^{2}$ $\mathrm{m}^{-3}$ for falling film (10 $\mu \mathrm{m}$ film thickness) and 9800 and 14800 $\mathrm{m}^{2} \mathrm{~m}^{-3}$ for microbubble column reactors.

A single groove $(0.5 \mathrm{~mm} \times 0.5 \mathrm{~mm})$ MSR was used for fluorination of 4-nitrotoluene in mixtures of acetonitrile and formic acid $(3: 2 \mathrm{v} / \mathrm{v})$ by Chambres et al. ${ }^{79}$ Further, they carried out selective fluorination of 1,3-dicarbonyl, ${ }^{80}$ aromatic, ${ }^{81}$ and heterocyclic compounds ${ }^{82}$ by batchwise procedures involving the passage of fluorine gas, diluted to a $10 \% \mathrm{v} / \mathrm{v}$ mixture in nitrogen, through stirred mixtures consisting of the substrate and the reaction medium (usually acetonitrile or formic acid). The experimental study of Chambres et al. ${ }^{79}$ demonstrates that "scale out" can be achieved by a simple replication of the single channel device described above and unoptimized fluorinations of representative 1,3-dicarbonyl and aromatic substrates were carried out in a 3-channel reactor.

The falling film MSR has been used for chlorination reaction. Wehle et al. ${ }^{83}$ studied chlorination of acetic acid by chlorine in a MSR at a temperature over $140{ }^{\circ} \mathrm{C}$, and the byproduct (dichloroacetic acid) was reduced significantly meaning that there is no need for a costly and time-consuming separation process. Further, Ehrich et al. ${ }^{84}$ demonstrated photochemical gas-liquid reaction by the selective photochlorination of toluene-2,4-diisocyanate. The space-time yield of 1Cl-TDI, formed by side chain chlorination of TDI, achieved in the MSR significantly exceeded the one of the batch reactor.

4.2. Nitration, Oxidations, Sulfonation, and Hydrogenation. Considering the explosive potential and corrosivity of nitrating agents, MSR are more suitable for such reactions. Antes et al. ${ }^{85}$ carried out nitration of naphthalene using $\mathrm{N}_{2} \mathrm{O}_{5}$ as a nitrating agent. For intense mixing of two fluids, interdigital mixers as well as the microstructures with the split-recombine technique were applied. Nitration in conventional batch operation requires very 
Table 5. Reaction Examples, Types of Reactors, and Results Obtained in Gas-Liquid Reactions

Table 5: Reaction Examples, Types of Reactors and Results Obtained in Gas-Liquid Reactions

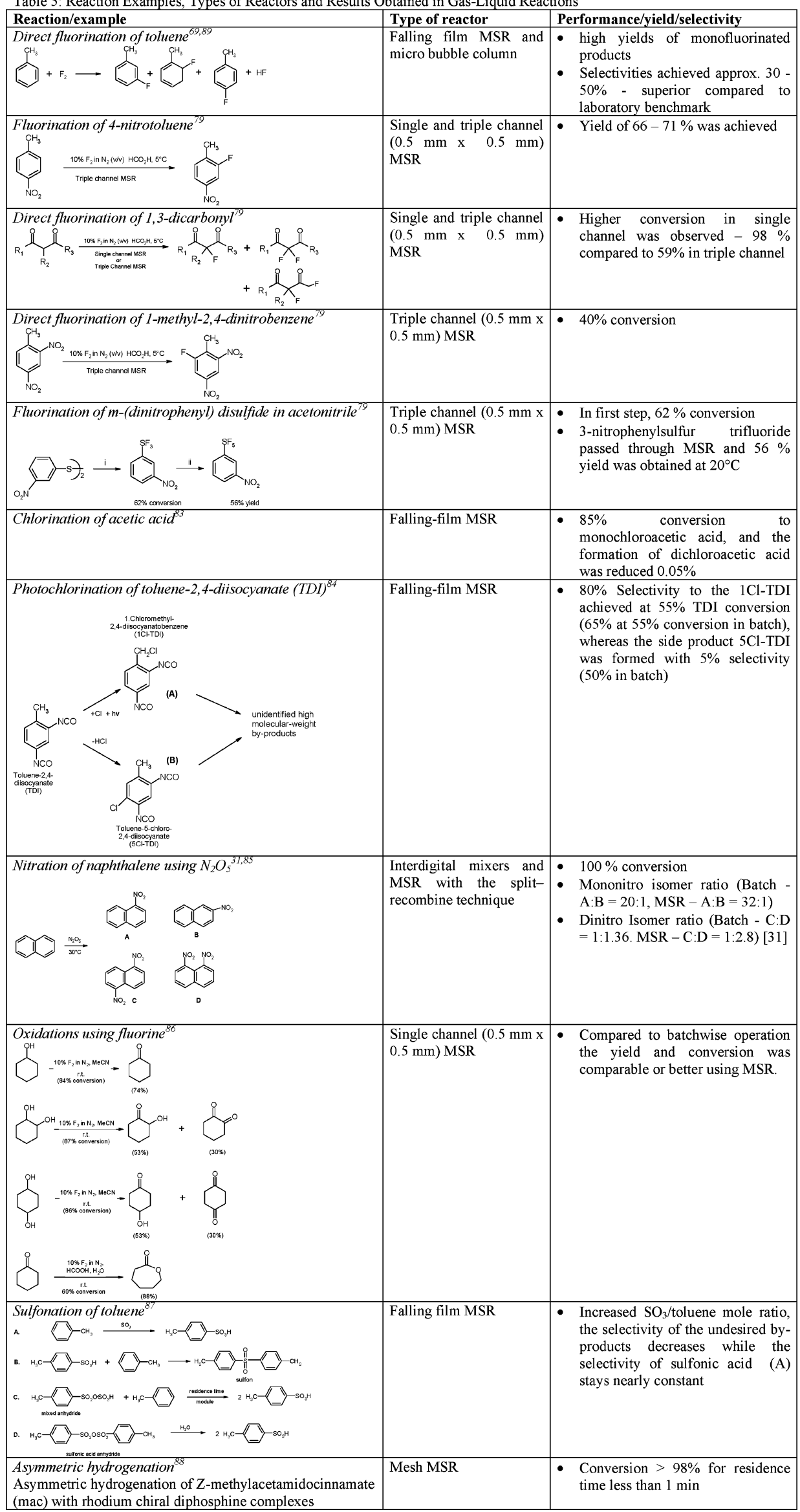


low temperature; the same reaction was carried out in the microreactor for temperature up to $50{ }^{\circ} \mathrm{C}$ and 8-fold excess of $\mathrm{N}_{2} \mathrm{O}_{5}$ with precise target of mononitro-naphthalene. In addition to the degree of nitration (number of nitro groups), different conditions of mass transport and contacting in the microreactors were used which resulted in the change in the isomeric ratio.

A continuous flow film gas-liquid MSR was used by Chambers et al. ${ }^{86}$ for the oxidation of aromatic alcohols and Baeyer-Villiger oxidation of ketones using elemental fluorine. The substrate in an appropriate solvent (acetonitrile or formic acid) was injected at a controlled rate by a syringe pump into the reaction channel. Compared to batchwise operation, the yield and conversion was comparable or better using MSR.

The sulfonation of toluene is one of the complex reactions compared to other elemental reactions as numerous side and consecutive reactions are possible. ${ }^{33}$ Müller et al. ${ }^{87}$ carried out sulfonation of toluene with gaseous $\mathrm{SO}_{3}$. It shows very encouraging results. With an increasing $\mathrm{SO}_{3} /$ toluene mole ratio, the selectivity of the undesired byproduct decreases while the selectivity of sulfonic acid stays nearly constant.

Abdallah et al. ${ }^{88}$ carried out the well-known gas-liquid asymmetric hydrogenation of $Z$-methylacetamidocinnamate (mac) with rhodium chiral diphosphine complexes using the mesh microreactor. The reactor has two $100 \mu \mathrm{m}$ deep cavities $(100 \mu \mathrm{L})$ separated by a micromesh in which the upper cavity is fed with the reacting gas while the other, the reacting chamber, contains the reacting liquid. Porosity of the mesh is $20-25 \%$ which leads to a gas-liquid interfacial area of $\sim 2000 \mathrm{~m}^{2} \mathrm{~m}^{-3}$ of liquid. Mesh MSR tests can be applied to very active catalysts such as the $\mathrm{Rh} /$ diop complex by operation in the continuous flow mode enabling short residence times $(1 \mathrm{~min})$. If longer residence times are required, the mesh microreactor can be operated batchwise by interrupting the liquid flow using appropriate valves.

\section{Liquid-Liquid Reactions}

5.1. Microstructured Reactor-A Laboratory Tool for Analysis. In the liquid-liquid system, a challenging task is to distinguish a contribution of mass transfer and reaction kinetics as they occur simultaneously. With newly developed online measurement techniques, ${ }^{90}$ MSR can be used as a laboratory tool to investigate the reaction kinetics.

5.1.1. Titration Reaction Using Slug (Segmented) Flow. The slug flow in a microreactor can be used as a tool to understand the mechanism of very fast homogeneous reactions. Burns and Ramshaw ${ }^{91}$ carried out neutralization using alternating slugs of two liquid phases to provide an environment for mass transfer and reaction within the microreactor. In the laboratory, the same reactions are being carried out using a buret and a beaker with a magnetic stirrer to achieve better mixing. However, the reaction is homogeneous and rapid which does not allow measuring mass transfer contribution and reaction kinetics separately.

Extraction of acetic acid from kerosene using a strong base $(\mathrm{NaOH}$ or $\mathrm{KOH})$ was carried out in a glass chip-based reactor with $380 \mu \mathrm{m}$ wide channel. ${ }^{91}$ The reaction is shown in the following:

$$
\begin{aligned}
& \mathrm{CH}_{3} \mathrm{COOH}+\mathrm{NaOH} \rightarrow \mathrm{CH}_{3} \mathrm{COONa}+\mathrm{H}_{2} \mathrm{O} \\
& \mathrm{CH}_{3} \mathrm{COOH}+\mathrm{KOH} \rightarrow \mathrm{CH}_{3} \mathrm{COOK}+\mathrm{H}_{2} \mathrm{O}
\end{aligned}
$$

A pH indicator was added to the $\mathrm{NaOH}$ solution, and the color change was observed along the length of the channel. From distance and flow velocity, color change time $(t)$ as well as mass transfer coefficients was investigated. Following empirical correlation of $t$ as a function of proportion of acetic acid consumed $(\beta)$, slug flow velocity $(u)$ and length of the slug $(L)$ was obtained:

$$
\begin{aligned}
& \text { rectangular soda lime glass }\left(d_{\mathrm{t}}=380 \mu \mathrm{m}\right) \cdot{ }^{91} \\
& \qquad t=4.67 \beta^{0.67} u^{-0.19} L^{0.94} \\
& \text { PTFE capillary }\left(d_{\mathrm{t}}=0.5,0.75 \text {, and } 1 \mathrm{~mm}\right):{ }^{92} \\
& \qquad t=3.41 \beta^{0.67} u^{-0.19} L^{0.94}
\end{aligned}
$$

Further, Dessimoz et al. ${ }^{93}$ carried out a similar reaction using strong acid, trichloroacetic acid, and bromothymol blue indicator. A saturated solution of bromothymol blue in deionized water was used to prepare aqueous solutions containing $\mathrm{NaOH}$ from 0.1 to $0.3 \mathrm{M}$. The trichloroacetic acid was dissolved in toluene or hexane with a concentration of $0.6 \mathrm{M}$. The $\mathrm{Y}$ shaped MSR generated parallel flow while the T shaped MSR was selected to generate slug flow. For the stabilization of slug flow in the T shaped MSR, the hexane/water system was used instead of toluene/water due to its high interfacial tension. For parallel flow, reactants trichloroacetic acid and $\mathrm{NaOH}$ have to diffuse from the interface and from the bulk, respectively, to the reaction plane where both concentrations become zero. The enhancement factor increases with increasing $\mathrm{NaOH}$ concentration due to the reduction of the distance between the reaction plane and the interface. In the case of slug flow, due to the internal circulation within the slug, the hydrodynamic boundary layer is reduced compared to the parallel flow, and therefore, the influence of the $\mathrm{NaOH}$ concentration, on the diffusion resistance in the aqueous phase, is not observed. Thus, the welldefined flow conditions in MSR allow the precise estimation of reaction parameters for the reactions which are difficult to carry out by conventional methods.

5.1.2. Online Analysis of Nitration. The conventional offline qualitative and quantitative analysis procedure comprises neutralization and phase separation followed by chromatographic
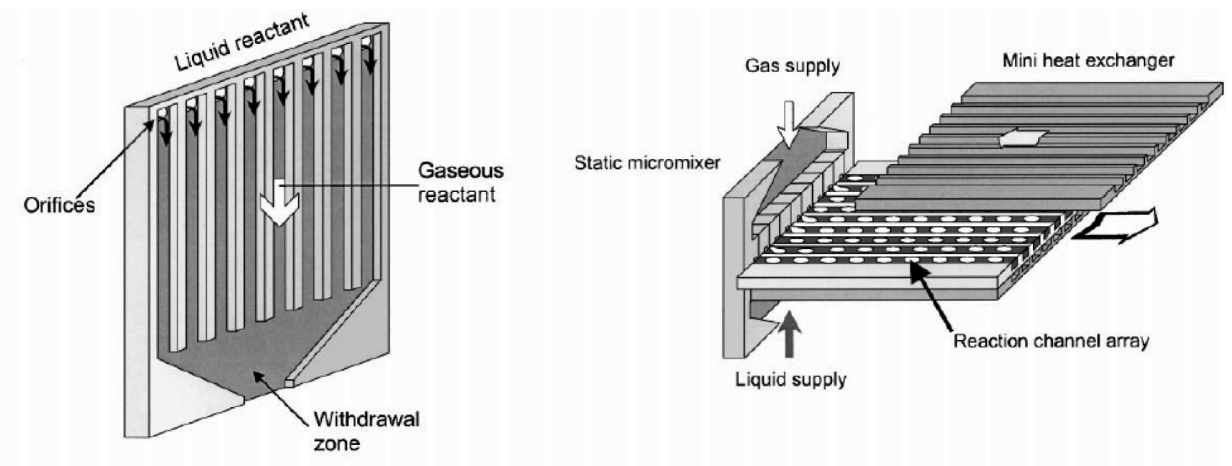

(a) falling film MSR

(b) micro bubble column

Figure 6. Schematic representation of a falling film microreactor (a) and a microbubble column (b). Adapted from the work of Jähnisch et al. ${ }^{69}$ (Reproduced with permission. Copyright Elsevier, 2000.) 
or spectrometric analysis. Collection of experimental data and evaluation of MSR performance are relatively time-consuming and of limited accuracy. Antes et al. ${ }^{94}$ used an online analysis technique to monitor the fast and strongly exothermic nitration reaction in MSR. The macroscopic nitration of toluene, a fast and strongly exothermic reaction, using conventional nitrating acid (a mixture of $\mathrm{H}_{2} \mathrm{SO}_{4}$ and $\mathrm{HNO}_{3}$ ) was due to a broad product spectrum comprised of mono and dinitrotoluene, oxidation and decomposition products, cresols, etc. A silicon MSR consisting of nine reactor channels in parallel (width $250 \mu \mathrm{m}$ each) was used and a commercially available HPLC system (HP 1084 with UV detection, Hewlett-Packard) was employed for the analysis. The sampling device was directly connected to the reactor outlet via a $\mathrm{T}$ shaped mixer allowing an instantaneous quenching by ice water. The reaction was run in the absence of sulfuric acid and only fuming $\mathrm{HNO}_{3}$ was used in the MSR experiments to obtain access to a significant cost-saving nitration process which only requires regeneration of nitric acid. Though the MSR is not an online technique in the true sense, the described experimental setup provides quick and valuable information about the composition of the reaction mixture, the degree of conversion, and the influence by process conditions.

Further, they coupled nitration of urea, nitration of dialkylsubstituted thioureas, with online infrared analysis. The reaction is strongly exothermic and is an important step in the synthesis of energetic plasticizer. Due to the transparency of silicon in the mid-infrared spectral range, Fourier transform infrared (FTIR) spectroscopy is a very suitable method for the analysis of chemical processes within silicon reactors. The progress of the reaction is spectroscopically monitored, revealed the mechanism, detected the intermediate formed during the reaction, and proposed a new mechanism-nitration of thioureas is based on subsequent nitrosation and nitration steps. Besides, FTIR microscopy was also applied for the spatial resolved quantitative analysis of $N^{\prime} N$-dialkyl- $N, N^{\prime}$-dinitro ureas. To monitor conversion within the reactor, infrared transmission spectra were systematically gathered along all the microchannels, and it was found that application of FTIR microscopy is a promising approach for the better understanding of such processes.

5.1.3. Extraction and Detection of Carbaryl Derivative. Smirnova et al. ${ }^{95}$ used a solvent extraction concentration method utilizing microchip technology which uses a thermal lens microscope (TLM) for the detection of low concentration substances. TLM, a type of photothermal spectroscopy, detects nonradiative relaxation (thermal) energy released after light absorption, and its sensitivity is demonstrated to be two or three orders higher than that of conventional spectrophotometry. It has demonstrated sensitive detection on a nanogram level. ${ }^{96} \mathrm{By}$ combining continuous reaction and TLM, various kinds of chemical procedures have been integrated into microchips.

Carbaryl pesticides were hydrolyzed in an alkaline medium to 1-napthanol; it was coupled with diazotized trimethylaniline and, then, extracted to toluene as a colored azo dye. ${ }^{95}$ Carbaryl can cause cholinesterase inhibition on humans, vertebrates, and insects, ${ }^{97}$ and it is necessary to carefully control its presence in natural water and soils. Two microchips with modified complexshape microchannels were used for mixing, reaction, extraction, and detection, and a thermal lens microscope was used for the detection of the colored product as shown in Figure 7. The detection point of the TLM was located at the center of the organic phase (shallow part of the microchannel), just halfway between the interface and microchannel sidewall. This integration greatly simplified the determination process and

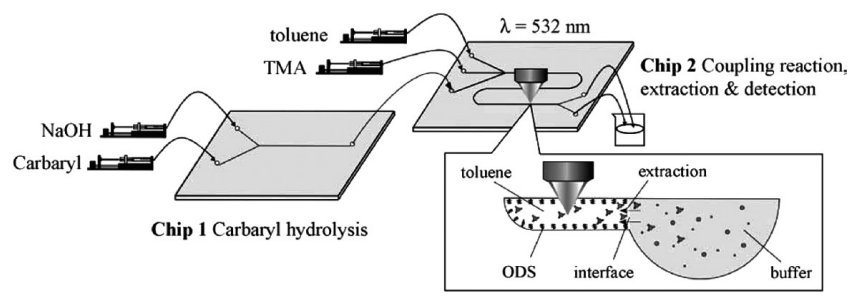

Figure 7. Experimental setup used for extraction and detection of carbaryl derivatives. Adapted from the work of Smirnova et al. ${ }^{95}$ (Reproduced with permission. Copyright Elsevier, 2006.)

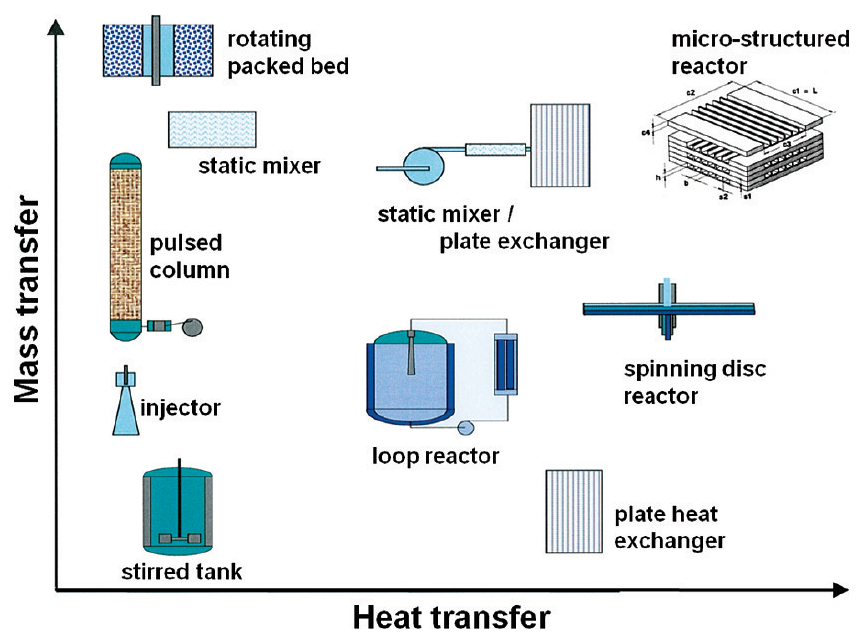

Figure 8. Benchmarking of microreactor. Adapted from the work of Jenck and Burille. 98

reduced analysis time. The results obtained suggested a good potential for implementing an on-site carbaryl analysis system.

5.2. Synthesis. Generally liquid-liquid extraction is carried out at ambient temperature while most of the biphasic reactions require heat addition or removal. The easy temperature profiling along the dimensions of the microreactor makes them more suitable for these applications. The heat and mass transfer characteristics of different reactors are depicted in Figure $8 .{ }^{98}$ It shows that microreactors offer superior performance compared to conventional equipment.

Microstructured reactors have already been used for some synthesis such as nitration, trans-esterification, vitamin synthesis, hydrolysis, etc. which is discussed in detail below.

5.2.1. Nitration Reaction. Nitration of Benzene. One of the most widely used reactions for benchmarking of chemical reactors for liquid-liquid application is the nitration reaction. The characteristic of this reaction is that it is an exothermic and mass-transfer limited reaction whose performance relies on efficient mass and heat transfer. The basic reaction scheme is shown in eq $8 .{ }^{66}$ The reaction is catalyzed by sulfuric acid that creates nitrating ions $\left(\mathrm{NO}_{2}{ }^{+}\right)$from $\mathrm{HNO}_{3}$.

$$
\begin{aligned}
& \mathrm{H}_{2} \mathrm{SO}_{4}+\mathrm{HNO}_{3} \leftrightarrow \mathrm{H}_{2} \mathrm{NO}_{3}^{+}+\mathrm{HSO}_{4}^{-} \\
& \mathrm{H}_{2} \mathrm{NO}_{3}^{+} \leftrightarrow \mathrm{NO}_{2}^{+}+\mathrm{H}_{2} \mathrm{O} \\
& \mathrm{NO}_{2}^{+}+\mathrm{C}_{6} \mathrm{H}_{6} \rightarrow \mathrm{C}_{6} \mathrm{H}_{5} \mathrm{NO}_{2}+\mathrm{H}^{+} \\
& \mathrm{H}^{+}+\mathrm{HNO}_{3} \leftrightarrow \mathrm{H}_{2} \mathrm{NO}_{3}^{+} \\
& \mathrm{H}^{+}+\mathrm{HSO}_{4}^{-} \leftrightarrow \mathrm{H}_{2} \mathrm{SO}_{4}
\end{aligned}
$$

All reactions mentioned above are assumed to take place within the acid phase. Poor mixing in this process reduces the transfer rates and leads to a buildup of dissolved nitrated product near the interface, which can be further nitrated to form often unwanted dinitro and trinitro compounds. ${ }^{99}$ Oxidation of the 


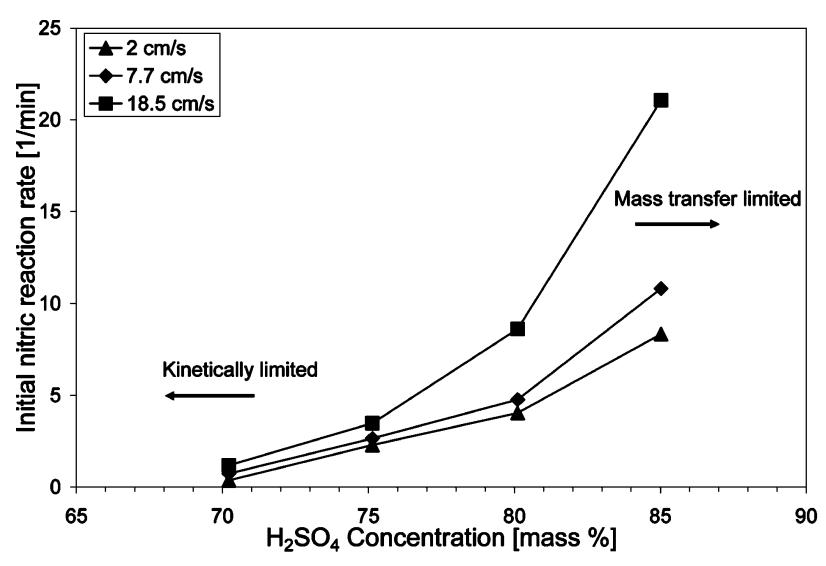

(a)

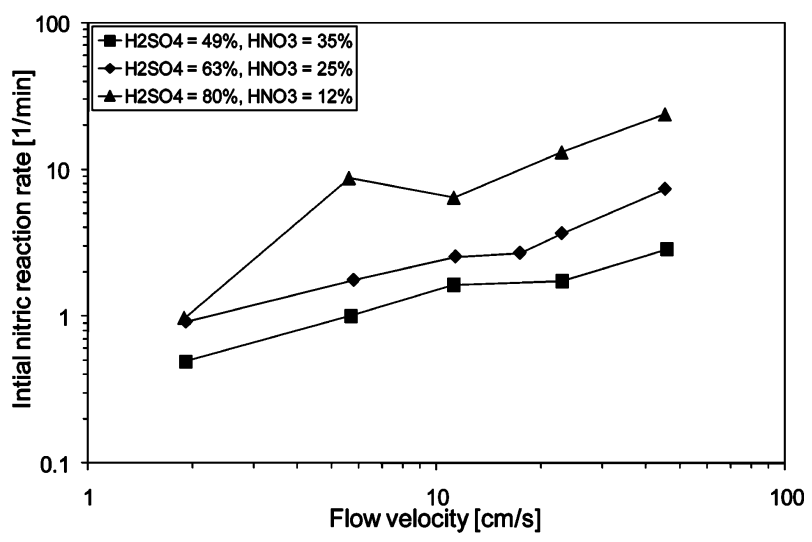

(b)

Figure 9. Nitration of aromatics-performance for varying flow velocities and $\mathrm{H}_{2} \mathrm{SO}_{4}$ strengths. (a) Nitration of benzene (reactor size $=178 \mu$ m, temperature $=90{ }^{\circ} \mathrm{C}, \mathrm{HNO}_{3}=4 \%$ ). (b) Nitration of toluene. Adapted from the work of Burns and Ramshaw. ${ }^{99}$ (Reproduced with permission. Copyright Taylor \& Francis, 2002.)

aromatic by $\mathrm{HNO}_{3}$ is also a common problem leading to unwanted byproducts such as phenols and picric acid in the case of nitration of benzene. The possible reactions for nitration of single ring aromatic to the mononitro compound, dinitrated byproduct, and phenolic byproduct. ${ }^{100}$ In order to enhance the transfer of aromatic from organic phase to aqueous phase where the reaction takes place prior to its oxidation to byproduct, it is necessary to have good dispersion. Besides, the amount of heat produced during the nitration of benzene is about $145 \mathrm{~kJ}$ per mole converted.

Burns and Ramshaw ${ }^{66}$ carried out nitration of benzene using a simple experimental setup. The narrow bore capillary tubes with various lengths $(50-180 \mathrm{~cm})$, diameters $(127-254 \mu \mathrm{m})$, and materials (316 stainless steel and PTFE) were used. Both phases having reactants, acid and organic, were introduced to a $\mathrm{T}$ connector to which the capillary tube (reactor) was attached downstream. The acid strengths used for the nitration was $63-85 \%$ for $\mathrm{H}_{2} \mathrm{SO}_{4}$ and from 2.6 to $4.9 \%$ for $\mathrm{HNO}_{3}$. The reactor tube was coiled within a controlled temperature bath. A strong acid, $83 \% \mathrm{H}_{2} \mathrm{SO}_{4}$, was used to produce highly mass transfer limited regime. Experiments were carried out for different flow velocities $\left(2-20 \mathrm{~cm} \mathrm{~s}^{-1}\right)$ and temperatures $\left(60\right.$ and $\left.90{ }^{\circ} \mathrm{C}\right)$. The small reactor showed higher organic transformation rates than the conventional reactor. The Arrhenius model was found to fit well with the effect of temperature on the reaction rate being proportional to $\mathrm{e}^{0.0293 T}$ for a $127 \mu \mathrm{m}$ reactor diameter and $\mathrm{e}^{0.0275 T}$ for $254 \mu \mathrm{m}$, respectively. Experiments with varied acid concentration showed that with increase in the $\mathrm{H}_{2} \mathrm{SO}_{4}$ concentration, the reaction rate increases due to increase of $\mathrm{NO}_{2}{ }^{+}$ions. The reaction rate was improved for higher flow velocities with high $\mathrm{H}_{2} \mathrm{SO}_{4}$ concentration where the production rate should depend on the mass transfer performance due to improved mixing.

Further, Burns and Ramshaw ${ }^{99}$ used stainless steel MSR with 127,178 , and $254 \mu \mathrm{m}$ channels for the nitration of benzene. The average nitric acid reaction rates were obtained for different concentrations of $\mathrm{H}_{2} \mathrm{SO}_{4}$, as shown in Figure 9. An exponential relationship between rate constant $(R)$ and flow velocity $(v)$ is given in the following.

$$
R=R_{\mathrm{V}} \mathrm{e}^{b \mathrm{v}}
$$

where $R_{\mathrm{V}}$ and $b$ are the empirical constants which depend on the $\mathrm{H}_{2} \mathrm{SO}_{4}$ concentration (e.g., $R_{\mathrm{V}}=7.45 \mathrm{~min}^{-1}$, and $b=0.055$ $\mathrm{cm}^{-1} \mathrm{~s}$ at $85 \% \mathrm{H}_{2} \mathrm{SO}_{4}$ ).

Further evaluation of mass transfer for the nitration of single ring aromatics shows that with increase in the flow velocity, the mass transfer increases. ${ }^{100}$ Experiments with different flow velocities, but identical residence times, carried out in a slug flow capillary microreactor, yielded differences in the conversion and the amount of byproduct formed. This enhancement of mass transfer for the same residence time but different flow velocity can be interpreted in terms of circulatory flow within the slugs - with increase in the flow velocity mass transfer increases. $^{101}$

Doku et al. ${ }^{102}$ carried out a similar mixed acid nitration as a model reaction to investigate mobility of multiphase solutions in a borosilicate glass microreactor $(200 \mu \mathrm{m} \times 100$ $\mu \mathrm{m})$ using an electrical field. The benzene was introduced as a microemulsion stabilized by a surfactant (sodium dodecyl sulfate), to provide the necessary ionic character to mobilize the organic phase under an electric field. Besides, the formation of the microemulsion droplets of the benzene increased the interfacial area with the nitrating phase increasing the mass transfer and transformation rates. The most important factors leading to the production of the mononitrobenzene were higher rates of microemulsion feed into the system, lower acid feed rate, and shorter reaction times (60 $\mathrm{s}$ maximum). Lower amounts of the byproducts, di- and trinitrobenzene, were found to occur owing to the deactivating nature of the nitro groups already present on the benzene ring and the limited amount of mixed acid introduced as a sample into the benzene stream serving as the main reagent.

In the industrial production, the main byproducts are dinitrobenzene (DNB), dinitrophenol (DNP), and picric acid at concentrations ranging from a few hundred to thousand parts per million. A comparison with existing patented industrial processes ${ }^{103,104}$ show that microreactors with same reaction rates results in lower byproduct formation (Table 6).

Nitration of Toluene. Burns and Ramshaw ${ }^{99}$ performed toluene nitration with $150 \mu \mathrm{m}$ bore PTFE tube varying acid strengths, reactor temperatures, and flow ratios. Initial studies of toluene nitration concentrated on the influence of temperature and flow ratio on the reaction rates for an acid mixture of $78 \% \mathrm{H}_{2} \mathrm{SO}_{4}$ and $7 \% \mathrm{HNO}_{3}$. The results showed a significant level of dinitrotoluene formation compared with the limited dinitrobenzene formation in the benzene process. Greater organic conversion was achieved when using higher concentration of acid. For the medium and high $\mathrm{H}_{2} \mathrm{SO}_{4}$ concentrations of $63 \%$ and $80 \%$, conversion to nitrotoluene and dinitrotoluene was continually enhanced as the acid/ organic ratio was increased. For the lower $\mathrm{H}_{2} \mathrm{SO}_{4}$ concentra- 
Table 6. Comparison of Capillary Reactor Performance with Conventional Patented Processes

\begin{tabular}{|c|c|c|c|c|c|c|c|c|}
\hline ref & inlet $\left({ }^{\circ} \mathrm{C}\right)$ & outlet $\left({ }^{\circ} \mathrm{C}\right)$ & $\mathrm{H}_{2} \mathrm{SO}_{4}(\operatorname{mass} \%)$ & nitrobenzene $(\%)$ & dinitrobenzene (ppm) & dinitrophenol (ppm) & time $(\mathrm{s})$ & rate $\left(\min ^{-1}\right)$ \\
\hline Alexanderson et al. ${ }^{103}$ & 80 & 128 & 60.6 & 89.5 & below 100 & 1000 & 120 & 0.9 \\
\hline Alexanderson et al. ${ }^{103}$ & 80 & 134 & 65.2 & 99.1 & 290 & 1800 & 120 & 2.1 \\
\hline Guenkel et al. ${ }^{104}$ & 95 & 120 & 69.5 & 90 & 50 & 1700 & 25 & 4.6 \\
\hline Burns and Ramshaw ${ }^{99}$ & 90 & 90 & 77.7 & 94 & 4000 & 350 & 24.4 & 5.9 \\
\hline Burns and Ramshaw ${ }^{99}$ & 90 & 90 & 72.2 & 60.7 & below 1000 & below 100 & 26.1 & 1.6 \\
\hline
\end{tabular}

Table 7. Comparison of Different Processes for the Production of Biodiesel with Microreactors ${ }^{a}$

\begin{tabular}{|c|c|c|c|c|c|}
\hline ref & process type & reactants & catalyst loading & residence time & conversion \\
\hline Dorado et al. ${ }^{107}$ & batch & oil + methanol & $1.26 \% \mathrm{NaOH}$ & $14 \mathrm{~h}$ & $90 \%$ \\
\hline Darnoko and Cheryan ${ }^{108}$ & batch & oil + methanol & $1 \% \mathrm{KOH}$ & $1 \mathrm{~h}$ & $98 \%$ \\
\hline Noureddini and Medikonduru ${ }^{109}$ & batch & oil + methanol & $0.2 \% \mathrm{NaOH}$ & $1 \mathrm{~h}$ & $90 \%$ \\
\hline $\mathrm{Xu}$ et al. ${ }^{110}$ & batch & oil + methanol & $30 \%$ lipase & $10 \mathrm{~h}$ & $92 \%$ \\
\hline Darnoko et al. ${ }^{111}$ & continuous & oil + methanol & $1 \% \mathrm{KOH}$ & $40 \mathrm{~min}$ & $89 \%$ \\
\hline Noureddini et al. ${ }^{112}$ & continuous & oil + methanol & $0.4 \% \mathrm{NaOH}$ & $6.6 \mathrm{~min}$ & $98 \%$ \\
\hline Hsu et al. ${ }^{113}$ & continuous & oil + methanol & lipase & $48 \mathrm{~h}$ & $96 \%$ \\
\hline Jachuck $^{106}$ & MSR - continuous & oil + methanol & $1 \% \mathrm{NaOH}$ & $3 \mathrm{~min}$ & $99 \%$ \\
\hline
\end{tabular}

${ }^{a}$ Adapted from the work of Jachuck. ${ }^{106}$

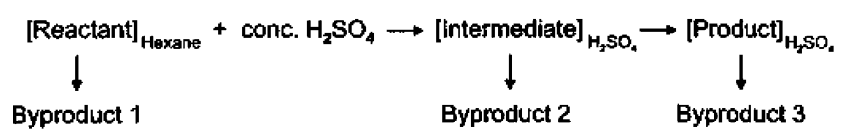

(a)

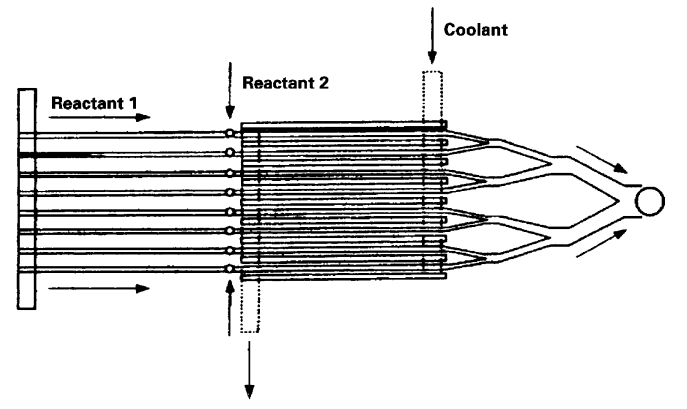

(b)

Figure 10. Production of vitamin precursor. (a) Reaction sketch (Adapted from the work of Löwe and Ehrfeld ${ }^{118}$ ). (Reproduced with permission. Copyright Elsevier, 1999.) (b) Reactor sketch (Adapted from the work of Wörz et al. ${ }^{119}$ ). (Reproduced with permission. Copyright Elsevier, 2001.)

tion of $49 \%$, this effect was reduced, and little improvement in organic conversion was gained by using acid/organic flow ratios greater than 2. A strong influence of flow velocity on transformation rates for toluene nitration was observed as given below:

$$
R \propto v^{m}
$$

where $m$ is an exponent which is 0.42 at $49 \% \mathrm{H}_{2} \mathrm{SO}_{4}$ and 0.92 at $80 \% \mathrm{H}_{2} \mathrm{SO}_{4}$.

Results from both benzene and toluene nitration have indicated that reaction rates in the range of $0.5-20 \mathrm{~min}^{-1}$ (Figure 9) can be achieved in a capillary reactor with significant reduction in byproducts formation compared to conventional processes. It may be due to different acid composition, isothermal environment, and fundamental difference in contacting two phases.

\subsubsection{Transesterification: Biodiesel Production. Biodiesel} is a mixture of alkyl esters produced from an elementary organic chemical reaction, transesterification, between organically derived triglycerides and short chain alcohol (ethanol or methanol). It can be used as an alternative to the petroleum diesel due to the chemical similarity. Conventional production in a batch reactor takes several hours due to diffusion resistance in two phase systems, while, using microreactors, biodiesel could be produced between 10 and 100 times faster than traditional methods. ${ }^{105}$ Conventional biodiesel production involves dissolving a catalyst in alcohol and, then, agitating the alcohol mixture with vegetable oil in a large reactor for several hours producing biodiesel and glycerin. This glycerin can be used to make soaps by neutralizing and removing the catalyst. The chemical biodiesel (methyl ester) production is given in the following:

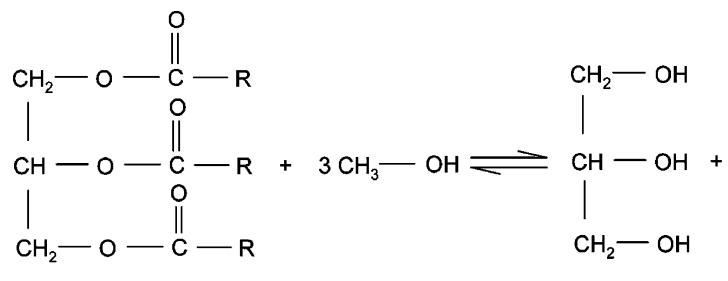

Triglyceride

Methanol

Glycerol<smiles>[R]C(=O)OC</smiles>

Methyl ester

This reaction is catalyzed by alkali $(\mathrm{NaOH}$ or $\mathrm{KOH})$. The important issues in this reaction are raw materials, reaction temperature, proportion of reactants, type and amount of catalyst, and biphasic mixing.

Most of the raw materials are produced in restaurants and farms in small amounts with various compositions, and therefore, it is difficult to collect and apply similar process conditions for the production of ASTM-certified biodiesel. Using microreactor technology, decentralized plants can be developed to produce the biodiesel in small amounts. Jachuck ${ }^{106}$ used microreactors for the production of biodiesel. The comparison 
of operating conditions and results obtained with conventional processes is presented in Table 7 . It shows that the highest conversion $(99 \%)$ was observed with significantly reduced residence time (3 $\mathrm{min})$.

5.2.3. Vitamin Precursor Synthesis. Vitamin A precursor synthesis is a commercially important reaction and is also used in the perfumery. In this reaction, the aqueous acidic agent diffuses into the organic phase comprised of solvent and pseudoionone where the reaction takes place. It is believed that the product goes back to the acidic phase. Reactant, intermediate, and product very quickly form byproduct which are mainly polymers as shown in Figure 10a. Concentrated sulfuric acid ${ }^{14-116}$ and a mixture of concentrated sulfuric acid and acetic acid $(7: 3)^{117}$ were used as acidic agents for a similar type of reaction, cyclization of pseudoionone to $\beta$-ionone. The flow properties such as viscosity, interfacial tension, and density change significantly as the reaction progresses. Moreover, it is believed that the byproduct formation is more pronounced with increase in the temperature. The important issues in this reaction are stable flow patterns, short residence time and isothermal reaction, the mixing of the two viscous phases, the quenching of the reaction by dilution with water, rapid separation of biphasic mixture, and separation of product from acidic phase.

For many years, the reaction could achieve a yield of $70 \%$ in the conventional semibatch reactor. The experiments carried out for studying kinetics by Wörz et al. ${ }^{119,120}$ required 2 min to mix the two viscous phases, to transfer the heat of reaction, to stop the reaction by dilution with water, and to separate the phases. The yield achieved was $25 \%$ which proves that the conventional laboratory technique is not adequate.

Löwe and Ehrfeld ${ }^{118}$ carried out reaction where the reactant is dissolved in $n$-hexane and concentrated sulfuric acid is a catalyst that forms the second liquid phase. In a continuous flow system consisting of a mixer and a cooler with defined residence times $(0.2 \mathrm{~s}$ in the mixer, $4 \mathrm{~s}$ in the cooler $)$ and a hot spot of $35 \mathrm{~K}$ in the mixing area, the yield can be increased up to $80-85 \%$. To reduce the hot spot to $1 \mathrm{~K}$, a microreaction system was developed with 32 reaction stainless steel channels $900 \mu \mathrm{m} \times 60 \mu \mathrm{m}$ in size separated by cooling channels (Figure 10b). The reactant and acid are mixed extremely fast in these microchannels and cooled simultaneously. Since the product is sensitive for consecutive reactions, it is obvious that the absence of backmixing increases the product yield.

The yield of the reaction depends on the residence time and on the maintenance of isothermal conditions. At a temperature of $50{ }^{\circ} \mathrm{C}$ and a residence time of $4 \mathrm{~s}$, in analogy to the industrial process, a yield of nearly $85 \%$ is achievable. For longer residence times at the given temperature the yield decreases rapidly. Compared to this result, at a temperature of $20{ }^{\circ} \mathrm{C}$, a maximum yield of $90-95 \%$ can be achieved with a residence time of $30 \mathrm{~s} .{ }^{119}$ The reaction is quenched by diluting the concentrated sulfuric acid/reactant mixture with water. This reaction has even a higher exothermicity and is carried out in a minimixer which is embedded in an additional layer. The byproduct formation was reduced by a half. The common drawback of microreactors is the danger of blockage due to high viscosity of the products and therefore requires careful construction.

5.2.4. Hydrolysis of $\boldsymbol{p}$-Nitrophenol Acetate. Ahmed et al. ${ }^{121}$ investigated the hydrolysis of $p$-nitrophenyl acetate (1), dissolved in toluene, with aqueous sodium hydroxide as a biphasic reaction as given in the following:<smiles>CC(=O)Oc1ccc([N+](=O)[O-])cc1</smiles>

(1)

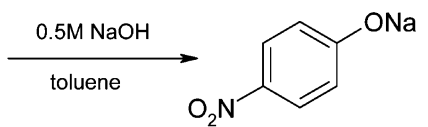

(2)
A solution of substrate (1) in toluene $(0.05 \mathrm{M})$ and an aqueous solution of sodium hydroxide $(0.5 \mathrm{M})$ were used. The reaction was performed in a MSR $(300 \mu \mathrm{m} \times 300 \mu \mathrm{m}$ microchannel, $400 \mathrm{~mm}$ length) or in a PTFE tube $(300 \mu \mathrm{m}$ internal diameter, $400 \mathrm{~mm}$ length). The hydrolysis of $p$-nitrophenyl acetate (1) was carried out under different reaction conditions in different reactors and a number of trends are presented in Figure 11. As can be seen from a comparison of yield obtained in MSR and in a conventional flask labeled (f) and (g), the gain is obvious. The reaction rate of the hydrolysis using a conventional flask is much lower than using MSR, and the difference between hydrolysis at room temperature $(\mathrm{g})$ and at $50{ }^{\circ} \mathrm{C}$ (f) is not significant at that time scale. Reactions labeled (d) and (e) were both carried out under similar reaction conditions, but in different reactors. These results show that the reaction in the PMMA (polymethyl methacrylate) MSR (d) performs slightly better than in the PTFE tubing (e). The better performance in the PMMA MSR is probably due to the slightly shorter segments (higher interfacial area) and their higher regularity. The different $\mathrm{T}$ junctions for creating the segmented flow might also play a role. As the PMMA MSR with its metal housing cannot be inserted in the microwave, the experiments at elevated temperature $(a-c)$ have been performed using PTFE tubing.

Ahmed et al. ${ }^{121}$ used segmented microflow to accelerate the hydrolysis of the acetate (1). Acetonitrile as a solvent together with aqueous sodium hydroxide created a homogeneous system, which was combined with an inert immiscible solvent (hexane) to divide the reaction solution into segments and to achieve intense mixing in the microchannel. There was no mass transfer across the interface and only rapid internal vortex fluid flow is achieved. The rate constant calculated assuming pseudo-first-order kinetics for the segmented flow $\left(k=0.2031 \mathrm{~s}^{-1}\right)$ is larger than the one for homogeneous laminar flow $\left(k=0.129 \mathrm{~s}^{-1}\right)$.

Further, Ahmed-Omer et al. ${ }^{122}$ observed an increased reaction rate in the laboratory flask for the toluene acetonitrile mixture as organic phase as compared to pure toluene due to reduced interfacial tension and increased partial solubility of organic phase in aqueous (and vice a versa). However, when the same comparison was made in microreactors, it was concluded that the effect of segmentation is stronger than the lower interfacial tension parallel flow. This is assigned due to the formation of higher interfacial area and internal circulations within the slugs of segmented flow.

5.3. Enzymatic Reactions. Currently, more and more attention is being paid to using enzymes as catalysts due to their ability to carry out reactions at ambient temperature and pressure with high selectivity. Maruyama et al. ${ }^{123}$ used an enzymatic reaction, laccase catalyzed degradation of $p$-chlorophenol, in a two phase flow microchannel $(100 \mu \mathrm{m}$ width, $25 \mu \mathrm{m}$ depth) fabricated on a glass plate $(70 \mathrm{~mm} \times$ $38 \mathrm{~mm}$ ). The enzyme (laccase), which is surface active (adsorbs spontaneously onto the liquid-liquid interface), was solubilized in a succinic aqueous buffer, and the substrate ( $p$-chlorophenol) was in isooctane. The degradation of $p$-chlorophenol occurs mainly at the aqueous-organic interface as given in the following: 


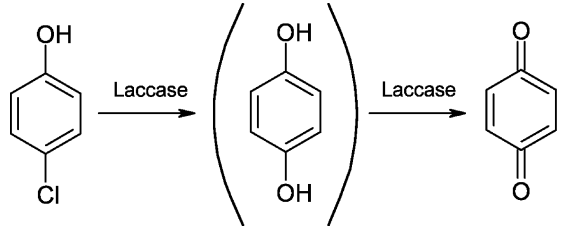

The reaction was carried out in a device depicted in Figure 12a. The side and top view of the microchannel is shown in Figure 12b. The confluent part of the microchannel was 100 $\mu \mathrm{m}$ wide and $25 \mu \mathrm{m}$ deep, while the inlet and outlet channels were $50 \mu \mathrm{m}$ wide and $25 \mu \mathrm{m}$ deep. The surface of the microchannel was partially modified with octadecylsilane groups to make it hydrophobic which allows clear phase separation at the end-junction of the microchannel. Assuming that diffusion of the substrate ( $p$-chlorophenol) is the rate-limiting step in the enzymatic degradation of $p$-chlorophenol, one-dimensional diffusion model was developed based on Fick's law. Using appropriate boundary conditions, the following relation between concentration of $p$-chlorophenol $(C)$ and the distance from the aqueous-organic interface $(x)$ was obtained as

$$
C(x, t)=C_{0} \operatorname{erf}\left[\frac{x}{\sqrt{4 D t}}\right]
$$

where $C_{0}$ is the initial $p$-chlorophenol concentration $(100 \mu \mathrm{M})$ and $D$ is the diffusivity of the $p$-chlorophenol concentration. The concentration $C(t)$ of $p$-chlorophenol at contact time $t$ in the microchannel can be written as

$$
C(t)=\frac{1}{d} \int_{0}^{d} C(x, t) \mathrm{d} x
$$

where $d$ is the width of organic phase, i.e. half of the channel width $(50 \mu \mathrm{m})$. The final conversion $X(t)$ of $p$-chlorophenol at the end of the microchannel can be given as

$$
X(t)=\left(1-\frac{C(t)}{C_{0}}\right) \times 100
$$

Further, the experiments for different microchannels dimensions showed that the glass surface and the aspect ratio of the microchannel are essential for obtaining stable two phase flow. The conversion of $p$-chlorophenol increased with increasing relative interface area. The results obtained using this model are compared with the experimental data and found to be in good agreement.

5.4. Phase Transfer Catalysis (PTC). Phase transfer catalysis is a common approach used to accelerate a biphasic reaction by ensuring a ready supply of necessary reagent to the phase in which the reaction occurs. ${ }^{124,125}$ It is an attractive alternative to conventional processes which can be inefficient due to high pressure and temperature requirements or due to low conversions or product selectivities. ${ }^{126}$ Enhanced mutual solubility and interfacial area facilitates the rate of reaction in the case of lipophilic and hydrophobic reactants. Each reactant is dissolved in the appropriate solvent, without regard necessarily to whether the solvents themselves are miscible, and then a phase transfer catalyst is added to promote the transport of one reactant into the other phase.

5.4.1. Hydrolysis of $\boldsymbol{p}$-Nitrophenyl Acetate 1. Ahmed-Omer et al. ${ }^{122}$ carried out experiments to combine segmented flow with other methods used in conventional batch chemistry to enhance the diffusion rate of biphasic reaction system. Hydrolysis of $p$-nitrophenyl acetate (1) is presented in the above section (see eq 12). A phase transfer catalyst, $10 \mathrm{~mol} \%$ tetrabutylammonium hydrogen sulfate $\left(\mathrm{Bu}_{4} \mathrm{NHSO}_{4}\right)$, was used

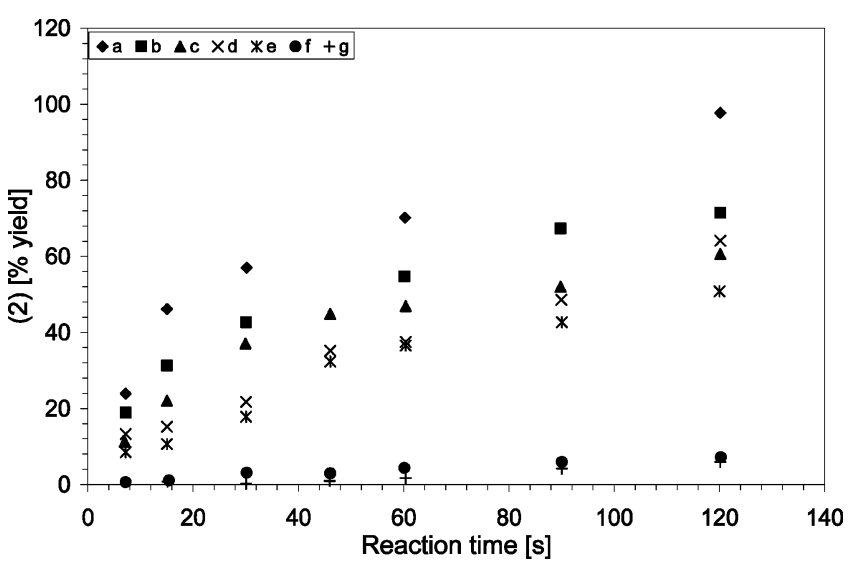

Figure 11. Yield of (2) during the hydrolysis of (1) using different equipment/conditions. (a) Short segmented flow (approximately $2 \mathrm{~mm}$ ) under microwave irradiation at $50{ }^{\circ} \mathrm{C}$. (b) Long segmented flow (approximately $10 \mathrm{~mm}$ ) under microwave irradiation at $50^{\circ} \mathrm{C}$. (c) Segmented flow in PTFE tubing heated in an oil bath at $50{ }^{\circ} \mathrm{C}$. (d) Segmented flow at room temperature in a PMMA reactor. (e) Segmented flow at room temperature in PTFE tubing. (f) Hydrolysis reaction at $50{ }^{\circ} \mathrm{C}$ in a flask with stirring. (g) Hydrolysis reaction at room temperature in flask with stirring. Adapted from the work of Ahmed et al. ${ }^{121}$ (Reproduced with permission. Copyright Wiley-VCH Yerlag GmbH \& Co. KGaA, 2006.)

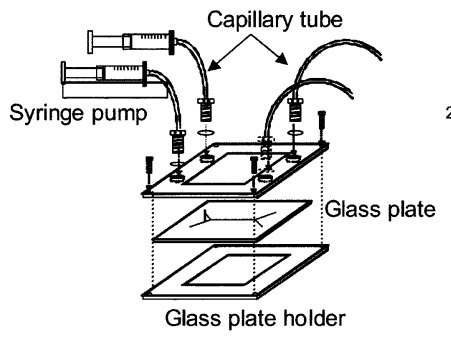

(a)

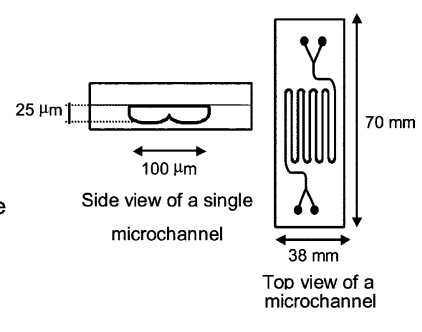

(b)
Figure 12. Microfluidic device and reaction system for degradation of p-chlorophenol. (a) Experimental setup. (b) Side and top view of the microchannel. Adapted from the work of Maruyama et al. ${ }^{123}$ (Reproduced with permission. Copyright Royal Society of Chemistry, 2003.)

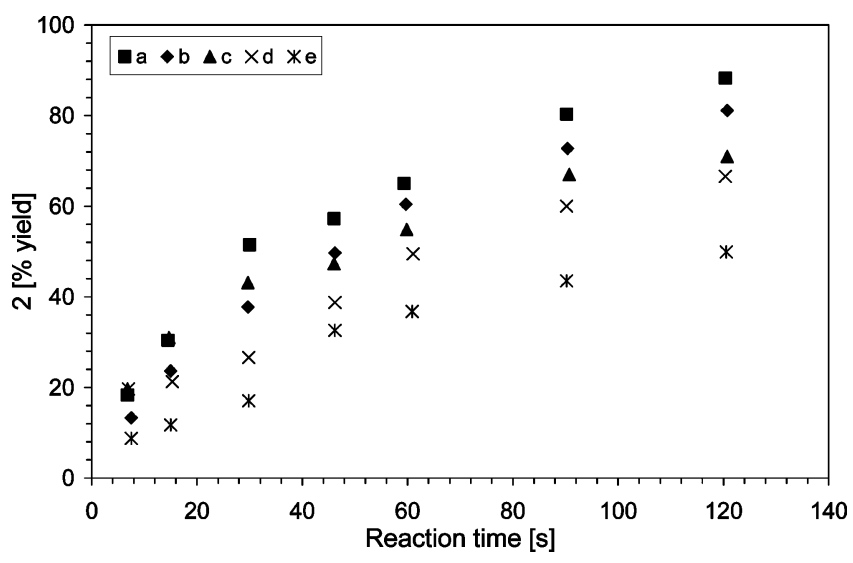

Figure 13. Hydrolysis of $p$-nitrophenyl acetate 1 to $p$-nitrophenyl acetate 2 in PTFE tubing (300 $\mu \mathrm{m}$ diameter microchannel, $400 \mathrm{~mm}$ length) using segmented flow conditions (organic phase: toluene): ${ }^{122}$ (a) $10 \mathrm{~mol} \%$ $\mathrm{Bu}_{4} \mathrm{NHSO}_{4}$ and sonication; (b) sonication; (c) microwave irradiation at 50 ${ }^{\circ} \mathrm{C}$; (d) $10 \mathrm{~mol} \% \mathrm{Bu}_{4} \mathrm{NHSO}_{4}$ at $20{ }^{\circ} \mathrm{C}$; (e) without PTC at $20{ }^{\circ} \mathrm{C}$. (Reproduced with permission. Copyright Elsevier, 2007.)

at $20{ }^{\circ} \mathrm{C}$ under segmented conditions. With PTC the increased reaction rate was observed compared to the case of segmented without phase transfer catalyst as shown in Figure 13. A further sonochemical technique was applied in which the microchannel tubing was immersed in the ultrasound bath during the reaction 


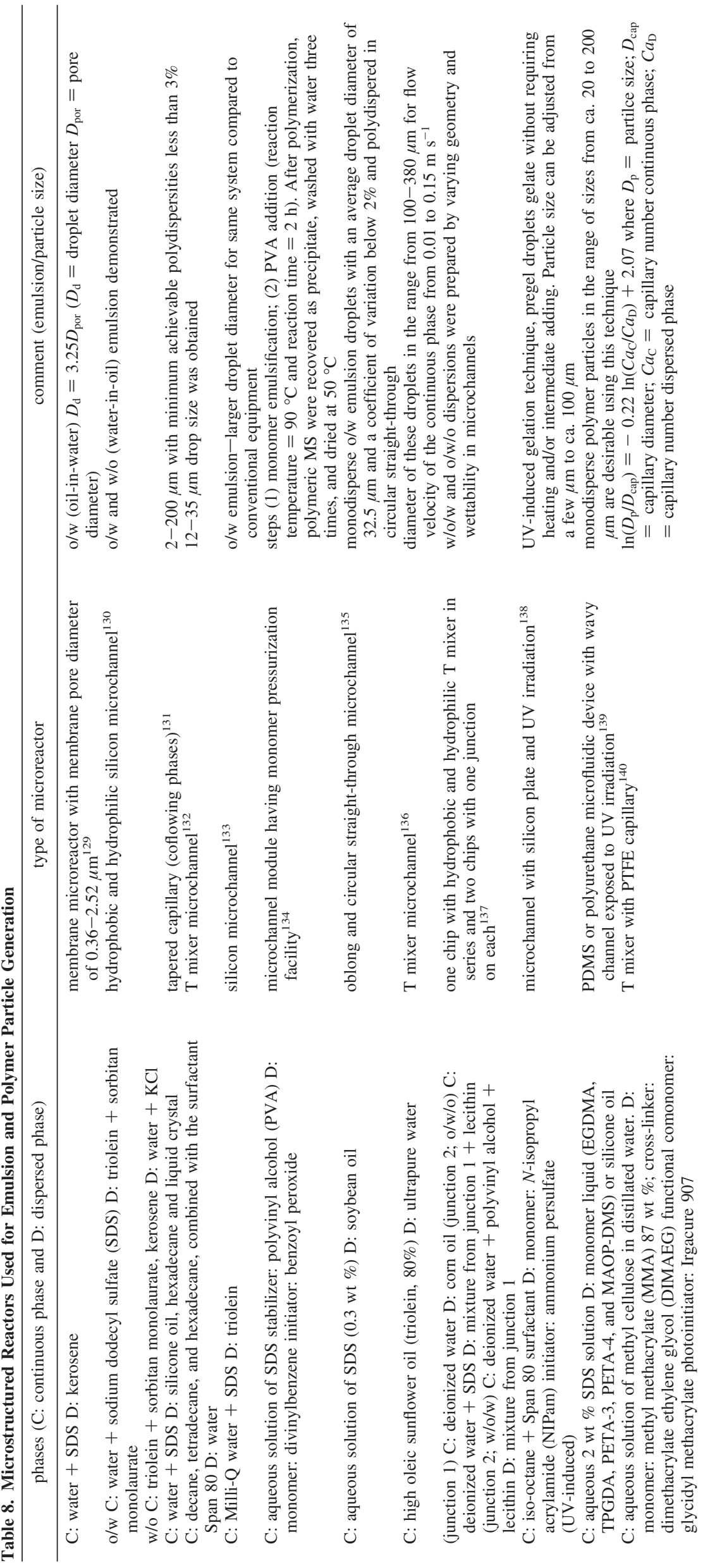


time. During sonication, some irregular sized segments $(1-10$ $\mathrm{mm}$ length) were formed together with some emulsion which increased the interfacial area. The highest reaction rates were observed when combining segmented flow, phase transfer catalyst, and sonication (Figure 13).

5.4.2. Benzylation Reaction. Alkylation reactions of $\beta$-keto esters are among the most important carbon-carbon bondforming reactions in organic synthesis. Ueno et al. ${ }^{127}$ carried out benzylation reaction of ethyl 2-oxocyclopentanecarboxylate (1) with benzyl bromide (2) in the presence of $5 \mathrm{~mol} \%$ of tetrabutylammoniun bromide (TBAB) as a phase transfer catalyst as given in the following:

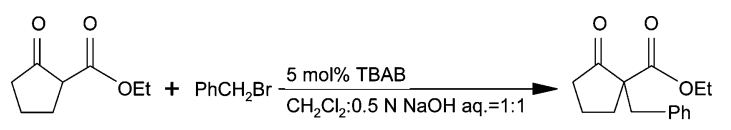

(1)

(2)

(3)

Experiments were carried out in a setup depicted in Figure 14a. The solution of dichloromethane containing $1(0.30 \mathrm{M}), 2$ $(0.45 \mathrm{M})$, and resorcinol dimethyl ether as an internal standard was introduced from one inlet whereas an aqueous solution containing sodium hydroxide $(0.50 \mathrm{~N})$ and TBAB $(0.015 \mathrm{M})$ was introduced through other inlet of the microchip under continuous flow conditions at ambient temperature.

Comparison with a microreactor with round-bottom flask for different stirrer speeds is presented in Figure 14b. In the microreactor, the reaction proceeded smoothly, and the desired alkylation product (3) was obtained in $57 \%$ yield at $60 \mathrm{~s}$ which was increased to over $90 \%$ after $300 \mathrm{~s}$. In the cases of the macroscale reactions, $2 \mathrm{~mL}$ of each of the reagent solutions were poured into a round-bottomed flask and stirred. Reaction rates were observed to be dependent on the stirring speedincreased stirring increased the yield. However, a much higher yield was obtained using a microreactor than that using standard batch system even with vigorous stirring which may be due to the larger interfacial areas available in the microreactor. In the further examinations in a microchip with several other substrates by keeping the flow rate constant for the mean residence time of 2 or $10 \mathrm{~min}$, the desired alkylated products were obtained. The PTC of various alkyl bromides as alkylation reagents with an $\alpha$-cyano ketone as substrate in microreactor gave higher yields than those in a round-bottomed flask with vigorous stirring at the same residence time.

5.5. Polymerization. The demand of polymeric materials is ever increasing because the higher strength polymers and composite materials are replacing the metals in automobiles, aircrafts, and many other applications. Some of the polymeric products are specialty chemicals which are manufactured in low volume with high product quality and are frequently used as copolymers. This is usually done in a batch reactor with the aim of manufacturing a product with acceptable quality apart from a safe and economic operation. In this case, it is important to have precise tuning of the parameters, especially temperature control, in order to get the desired product. Polymerization reactions in conventional reactors often suffer from inefficient heat removal which results in nonhomogeneity and does not allow to control the molecular weight distribution.

Different polymerization such as suspension or emulsion (which uses two immiscible liquids) can be carried out in a two phase microreactor. In suspension polymerization, the monomer is initially dispersed in the continuous aqueous phase by the combined action of surface-active agents. The commonly used equipment for suspension polymerization is an agitated stirred tank. The agitation intensity and the properties of the suspending agent determine the sizes of the dispersed monomer drops. The polymerization occurs in the monomer droplets which become more sticky and viscous as conversion proceeds. Finally, they are transformed into rigid, spherical polymer particles of size $50-500 \mu \mathrm{m},{ }^{128}$ and the properties of the final particles depend on those of the initial drops which can be precisely tuned in the microreactors.

The most important technical point for commercialization of microreactor polymerization is stable continuous operation without any troubles such as clogging. Emulsion in the microfluidic was first created using membrane emulsification process by Nakashima et al., ${ }^{129}$ and several attempts have been made to generate emulsion and carry out polymerization in the microreactors as listed in Table 8 . Most of the literature data show that the monodispersed emulsion and thus polymer particles can be achieved using microstructured devices.

\section{Three-Phase (Gas-Liquid-Solid) Reactions}

In the gas-liquid-solid MSR, catalyst is incorporated either as a packed bed or as a coating. In the packed bed reactors, standard porous catalysts are incorporated and the fluid streams are brought into contact. In the falling-film microreactor, the catalyst is incorporated as thin nonporous films or as particles in alumina-coated walls. ${ }^{33}$ Different methods of deposition of film on the solid surface are presented in Table 9.

Gas-liquid-solid reactions, mainly hydrogenations, studied in the literature are summarized in Table 10. Losey et al. ${ }^{73,161}$ used a micropacked-bed reactor (Figure 15) to carry out the hydrogenation of cyclohexene, a model reaction for multiphase reactors, over standard platinum supported on alumina powder (platinum content was either 1 or $5 \mathrm{wt} \%$ ). Gas and liquid inlet flows are split among several channels that deliver the reactants continuously and cocurrently to 10 reaction chambers. A wide channel perpendicular to these small channels is used to deliver the catalyst slurry to the reaction chambers which is filtered at the end. The small particles provide the high surface areas for improved gas-liquid mixing, but they also represent a challenge in terms of pressure drop and fluid distribution among the ten parallel channels.

Further, Losey et al. ${ }^{161}$ used a device (Figure 16) containing staggered arrays of $50 \mu \mathrm{m}$ diameter columns within the channels to provide both catalyst support (porous silicon) and static mixing for cyclohexene hydrogenation. These posts, $50 \mu \mathrm{m}$ in diameter and $300 \mu \mathrm{m}$ tall, are arranged in staggered arrays and provide for a void fraction of 60\% ( 20000 columns per device). Compared with packed-beds, which for spherical packing have a void fraction near $40 \%$, the microstructured channels have a reduction in pressure drop with a small reduction in catalyst volume.

A microstructured falling-film reactor was used for hydrogenation of nitrobenzene to aniline $\left(\Delta H_{\mathrm{r}}=-545 \mathrm{~kJ} \mathrm{~mol}^{-1}\right)$ in ethanol by Yeong et al. ${ }^{163}$ The reaction can proceed along different pathways and involved several intermediates which can also react with each other which can controlled by precise temperature control. The catalyst, palladium, was deposited as films or particles via sputtering, UV decomposition of palladium acetate, or incipient wetness impregnation. The results show that such a reaction is feasible in the falling film MSR provided that a suitable catalyst incorporation methods are employed. The deactivation of catalyst was observed through the formation of organic compounds on the catalyst surface and palladium loss. Among all, $\gamma$-alumina supported palladium prepared through incipient wetness impregnation was found to be reasonably robust. 
Table 9. Different Techniques Used to Increase Surface Area in Catalytic Wall MSR

\begin{tabular}{|c|c|}
\hline coating layer & technique \\
\hline \multicolumn{2}{|c|}{ metal oxide coatings } \\
\hline $\begin{array}{l}\text { alumina }^{141-143} \\
\text { alumina }^{144} \\
\text { alumina, }^{145} \text { silica, } \\
\text { alumina }^{148} \\
\gamma \text {-alumina }{ }^{149} \\
\mathrm{Al}_{2} \mathrm{O}_{3}, \mathrm{ZnO}^{14} \text {, and } \mathrm{CeO}_{2}{ }^{150} \\
\text { zeolite }^{151,152} \\
\text { zeolite }^{153-155} \\
\text { alumina }^{156} \\
\text { Au/TiO } \mathrm{TiO}_{2} \text { porous catalyst }\end{array}$ & $\begin{array}{l}\text { anodic oxidation of aluminum } \\
\text { anodic oxidation of AlMg microstructured reactor wall } \\
\text { sol-gel technique } \\
\text { high temperature treatment of Al containing steel (DIN } 1.4767 \mathrm{FrCr} \text { alloy) } \\
\text { wash-coating } \\
\text { electrophoretic deposition } \\
\text { zeolite coated microchannel reactors } \\
\text { direct formation of zeolite crystals on metallic structure } \\
\text { chemical vapor deposition (CVD) } \\
\text { flame spray }\end{array}$ \\
\hline \multicolumn{2}{|c|}{ carbon based coatings } \\
\hline $\begin{array}{l}\text { carbon coating }{ }^{158} \\
\text { carbon nanofibers }^{159,160}\end{array}$ & $\begin{array}{l}\text { carbonization of polymers } \\
\text { thermal chemical vapor deposition }\end{array}$ \\
\hline
\end{tabular}

Another method of three phase contacting is the use of mesh MSR. Abdallah et al. ${ }^{88}$ studied the heterogeneous hydrogenation of $\alpha$-methylstyrene to cumene using mesh MSR. Two catalysts $\mathrm{Pd} / \mathrm{Al}_{2} \mathrm{O}_{3}$ and $\mathrm{Pt} / \mathrm{Al}_{2} \mathrm{O}_{3}$ were used. The activity of the catalyst is too high resulting in mass transfer limitations. A global mass transfer coefficient of $\left(1-2 \mathrm{~s}^{-1}\right)$ was roughly estimated applying "in series mass transfer resistances concept" a fast first-order reaction which is in the range of those found in commercial pressure reactors.

A channel MSR without any internals for mixing can also be used for three phase reactions. Födisch et al. ${ }^{165}$ carried out hydrogenation of $p$-nitrotoluene to $p$-toluidin in microchannel reactors using different ways of preparation of the Pd catalyst. Practically, this reaction is free of byproduct i.e. selectivity to $p$-toluidine is $100 \%$. Depending on the operating conditions, the conversion was varied from $58-98 \%$ in MSR. The conversion for an electrodeposited palladium was $58 \%$, that for chemical deposited palladium was in between 58 and $98 \%$, that for impregnated catalyst on an electro-oxidized nanoporous substrate was $89 \%$, and that for a fixed-bed catalyst was $85 \%$. Though the best MSR conversion is similar to that of a conventional fixedbed reactor, the increased heat removal allowed a pronounced decrease in reaction time down to some few minutes. ${ }^{166}$

\section{Conclusions and Outlook}

In this review, different types of conventional and microstructured reactors (MSR) applied to carry out multiphase reactions are presented. It is known that MSR are suitable for reactions with fast intrinsic kinetics, requiring better transport and inherent safety, or performed under extreme operating conditions (e.g., high temperature, pressure, etc). The results presented herein clearly indicate that for such reactions MSR offer superior performance in comparison to the conventional equipment.

From the fluid dynamic point of view, fluid-fluid MSR provide well-defined flow regimes. In general, slug and parallel/annular flow patterns are commonly observed. In most of the examples presented, the slug (Taylor) flow demonstrated advantages over parallel flow due to its double mass-transfer mechanisms: internal convection within the slug and interfacial diffusion between two slugs. The main parameters controlling the flow pattern are the MSR geometry, fluid viscosity, and interfacial tension.

Many chemical transformations in conventional reactors proceed under mixed kinetic and transport control and measurement of their intrinsic kinetics often requires an elimination or at least definition and control of material transport. ${ }^{167}$ Analysis of the intrinsic kinetics of two phase reactions affected by mass-transport can be complex except for the extreme cases where intrinsic reaction rates are either very high or very low. Using the slug flow technique, the transport (mass transfer) and kinetics contribution of such reactions can be studied. ${ }^{91}$

Effective utilization of small amount of chemicals due to the high rate of heat and mass transfer provides a good environment for finding new routes for synthesis which are

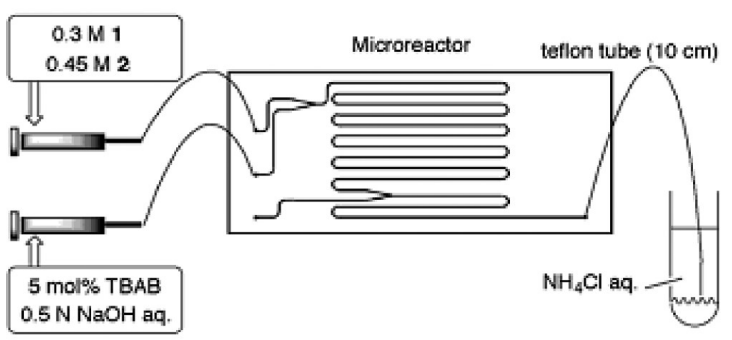

(a)

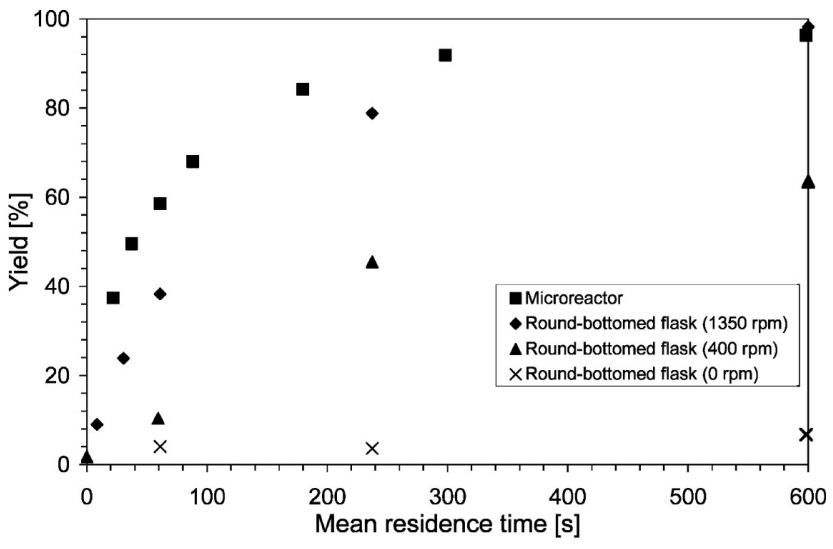

(b)

Figure 14. Benzylation reaction. (a) Microreactor used (channel $200 \mu \mathrm{m}$ width, $100 \mu \mathrm{m}$ depth, and $45 \mathrm{~cm}$ length and Teflon tube diameter $200 \mu \mathrm{m}$, length $10 \mathrm{~cm}$ ). (b) Yield vs mean residence time. Adapted from the work of Uneo et al. ${ }^{127}$ (Reproduced with permission. Copyright Royal Society of Chemistry, 2003.) 
Table 10. Reaction Examples, Types of Reactors, and Results Obtained in Gas-Liquid-Solid Reactions

\begin{tabular}{|c|c|c|}
\hline Reaction/example & Type of reactor & Performance/yield/selectivity \\
\hline $\begin{array}{l}\text { Hydrogenation of cyclohexene } e^{73,161} \\
\underset{0.1-0.25 \mathrm{MPa}}{\stackrel{\mathrm{H}_{2}, \mathrm{Pt}_{\mathrm{Al}} \mathrm{O}_{3}}{\longrightarrow}}\end{array}$ & 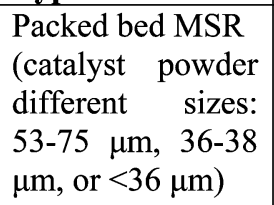 & $\begin{array}{l}\text { - Improved mass transfer }\left(\sim 10 \mathrm{~s}^{-1}\right) \\
\text { over its macroscale counterpart }(100 \\
\text { time-fold) }\end{array}$ \\
\hline Hydrogenation of $\alpha$-methylstyrene ${ }^{162}$ & Packed bed MSR & $\begin{array}{l}\text { - } \text { Conversion } 20-100 \% \\
\text { - The initial reaction rates } \sim 0.01 \\
\text { mmol } \mathrm{min}^{-1} \text { per channel - favorable } \\
\text { compared with the intrinsic kinetics } \\
\text { in the literature }\end{array}$ \\
\hline Hydrogenation of cyclohexene $e^{73}$ & $\begin{array}{l}\text { Channels with } \\
\text { staggered column }\end{array}$ & $\begin{array}{l}\text { - Mass transfer coefficients } 3-7 \mathrm{~s}^{-1} \\
\text { - Initial reaction rates } 6.5 \times 10^{-5} \mathrm{~mol} \\
\min ^{-1} \mathrm{~m}^{-2} \text { with the porous silicon } \\
\text { support vs } 4.5 \times 10^{-5} \mathrm{~mol} \mathrm{~min}^{-1} \mathrm{~m}^{-2} \\
\text { with the powdered catalyst }\end{array}$ \\
\hline $\begin{array}{l}\text { Hydrogenation of nitrobenzene to } \\
\text { aniline }{ }^{163}\end{array}$ & $\begin{array}{ll}\text { Falling } & \text { film } \\
\text { reactor } & \end{array}$ & $\begin{array}{l}\text { - MSR } 394 \mathrm{kmol}^{2} \text { aniline } \mathrm{m}^{-3} \text { reactor } \\
\left(\mathrm{NB}-0.1 \mathrm{~mol} \mathrm{~L}^{-1} \text {, temperature } 60\right. \\
{ }^{\circ} \mathrm{C} \text {, pressure } 1 \mathrm{bar} \text { ) while a batch } \\
\text { reactor } 204 \mathrm{kmol}^{-1} \text { aniline } \mathrm{m}^{-3} \text { reactor } \\
\left(\mathrm{NB} 0.4 \mathrm{~mol} \mathrm{~L}^{-1} \text {, temperature } 125\right. \\
\left.{ }^{\circ} \mathrm{C} \text {, pressure } 20 \mathrm{bar}\right)\end{array}$ \\
\hline $\begin{array}{l}\mathrm{AN} \\
\text { (NB -nitrobenzene, NSB - nitrosobenzene, } \\
\mathrm{PHA} \text { - phenylhydroxylamine, AN - aniline, } \\
\mathrm{AOB} \text { - azoxybenzene, AB - azobenzene, } \\
\mathrm{HOB} \text { - hydrazobenzene) }\end{array}$ & & \\
\hline Hydrogenation of p-nitrotoluene $e^{165,166}$ & Channel MSR & 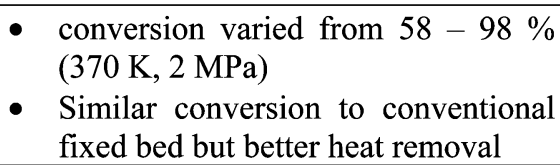 \\
\hline Hydrogenation of $\alpha$-methylstyrene $e^{33,88}$ & Mesh MSR & - Mass transfer coefficient $1-2 \mathrm{~s}^{-1}$ \\
\hline
\end{tabular}

economical and environmentally benign. MSR are powerful tools for studying the intrinsic kinetics of highly exothermic and mass-transfer limited reactions. The high interfacial area available can guarantee the absence of mass-transfer limitation in the reaction environment. Besides, the small dimen-

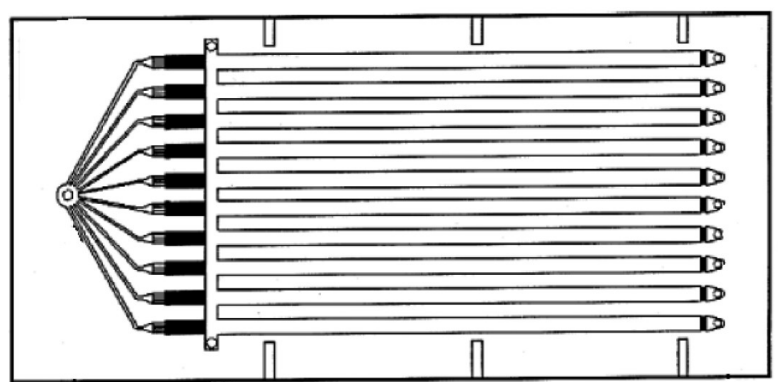

(a) sions facilitate homogeneous temperature along the cross section at a given axial position which helps to dissipate the heat released during the reaction. Due to small hold-up of hazardous chemicals in such productions, the inherent safety can be guaranteed.

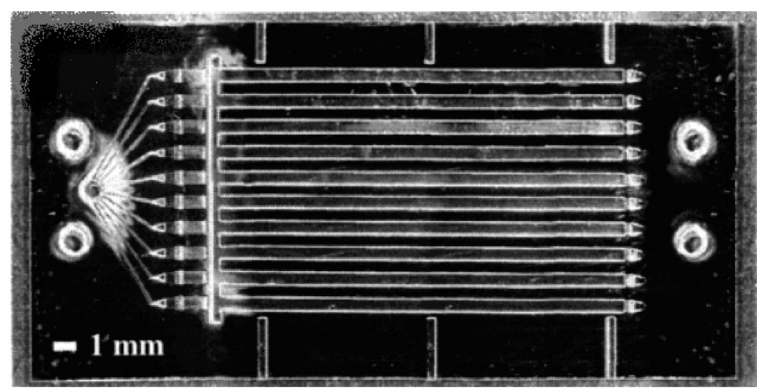

(b)

Figure 15. Packed-bed MSR. (a) Top silicon layer illustrating fluid manifold to 10 parallel fixed-bed reaction channels. (b) Photomicrograph of multichanel reactor chip. Adapted from the work of Losey et al. ${ }^{73}$ (Reproduced with permission. Copyright American Chemical Society, 2001.) 


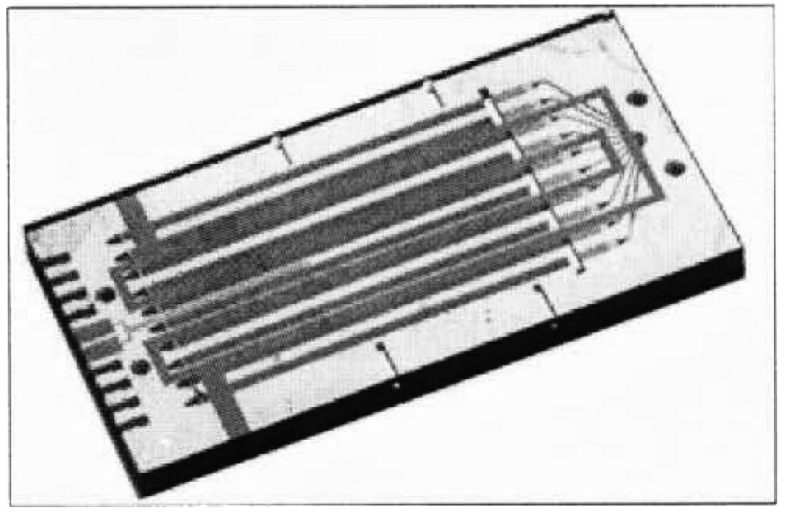

(a)

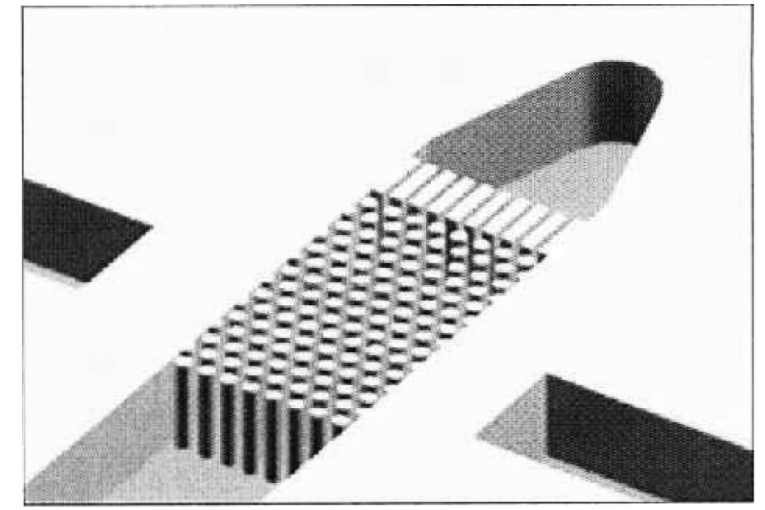

(b)

Figure 16. (a) Ten-channel microstructured reactor. (b) Channel view of catalytic microstructured support columns. Adapted from the work of Prof. K. F. Jensen. ${ }^{168}$

Though the MSR show many advantages, there are several case-specific constraints that hamper the use of MSR for multiphase reactions. In the catalytic MSR, the performance is adversely affected by catalyst deactivation. Effective in situ catalyst regeneration, therefore, becomes necessary, since the simple catalyst change practiced in conventional reactors is usually no longer an option. The thickness of the microreactor catalytic wall is often greater than the internal diameter of the channel and, therefore, may impede heat transfer for highly exothermic reactions, leading to nonisothermal behavior.

Reactions involving highly viscous materials or suspended particles are difficult to carry out in MSR. Moreover, the reliable modeling of such systems at the microscale is still poorly developed. Last, but very important, reliable scaling up needs to be resolved in order to achieve throughput in the industrially required range. If one fails to achieve a uniform distribution over parallel microstructured elements, many of the advantages of MSR will be forfeited.

\section{Acknowledgment}

The authors thank Prof. Albert Renken for valuable comments. Financial support from the Swiss National Science foundation is highly appreciated.

\section{Literature Cited}

(1) Dudukovic, M. P.; Larachi, F.; Mills, P. L. Multiphase catalytic reactors: A perspective on current knowledge and future trends. Catal. Rev.Sci. Eng. 2002, 44 (1), 123-246.

(2) Renken, A. Unsteady-state operation of continuous reactors. Int. Chem. Eng. 1984, 24 (2), 202-213.

(3) Kobayashi, D.; Matsumoto, H.; Kuroda, C. Dynamic operation for process intensification of batch emulsion polymerization under indirect ultrasonic irradiation. Kagaku Kogaku Ronbunshu 2008, 34 (2), 254-260.

(4) www.imm-mainz.de (accessed 2009).

(5) Renken, A.; Hessel, V.; Löb, P.; Miszczuk, R.; Uerdingen, M.; KiwiMinsker, L. Ionic liquid synthesis in a microstructured reactor for process intensification. Chem. Eng. Process.: Process Intens. 2007, 46, 840-845.

(6) http://www.fzk.de (accessed 2009).

(7) http://www.ehrfeld.com/ (accessed 2009).

(8) Kirschneck, D.; Tekautz, G. Integration of a microreactor in an existing production plant. Chem. Eng. Technol. 2007, 30 (3), 305-308.

(9) www.mikroglas.com (accessed 2009).

(10) www.micronit.com (accessed 2009).

(11) http://www.ltf-gmbh.de (accessed 2009).

(12) www.syrris.com (accessed 2009).

(13) Stange, O.; Schael, F.; Herbstritt, F.; Gasche, H.-E.; Boonstra, E.; Mukherjee, S. Modular micro process technology - new devices and applications. In 10th International Conference on Microreaction Technology, New Orleans; American Institute of Chemical Engineers: New York, 2008.

(14) Johnson, B. R. Multi-step chemical processes in a Modular Reactor from Alfa Laval. In VDI Berichte; 2008; pp 171-176.

(15) Grétillat, M. A.; Paoletti, F.; Thiébaud, P.; Roth, S.; KoudelkaHep, M.; De Rooij, N. F. A new fabrication method for borosilicate glass capillary tubes with lateral inlets and outlets. Sens. Actuators, A 1997, 60 $(1-3), 219-222$.

(16) Short, P. L. Microreactors hit the major leagues. Chem. Eng. News 2008, 86 (42), 37-38.

(17) Krummradt, H.; Koop, U.; Stoldt, J. Experiences with the use of microreactors in organic synthesis. In 3rd International Conference on Microreaction Technology, Frankfurt, Germany; Springer: Berlin, 2000; pp $181-186$.

(18) Kwak, B. S. Development of chiral pharmaceutical fine chemicals through technology fusion. Chimica Oggi 2003, 21 (1-2), 23-26.

(19) Dapremont, O.; Zeagler, L.; Dubay, W. Reducing cost through continuous processing. SP2 www.sp2.uk.com.

(20) Proctor, L. D.; Warr, A. J. Development of a continuous process for the industrial generation of diazomethane. Org. Process Res. Dev. 2002, $6(6), 884-892$.

(21) Wille, C.; Gabski, H. P.; Haller, T.; Kim, H.; Unverdorben, L.; Winter, R. Synthesis of pigments in a three-stage microreactor pilotplantan experimental technical report. Chem. Eng. J. 2004, 101 (1-3), 179185.

(22) Pöchlauer, P.; Bohn, L.; Kotthaus, M.; Kraut, M.; Vorbach, M.; Wenka, A.; Schubert, K. F. Micro-Structured Devices for the chemical research, process development, and production-opportunities and Limits. In Micro-strucutred devices for chemical research. process development and production - opportunites and limites; F. Hoffmann-La Roche Ltd: Basel Switzerland, 2006.

(23) Poechlauer, P.; Kotthaus, M.; Vorbach, M.; Deak, M.; Zich, T.; Marr, R. Stepwise execution of exothermic reactions with participation of carbocations, WO2006125502A1, 2006.

(24) Roberge, D. M.; Zimmermann, B.; Rainone, F.; Gottsponer, M.; Eyholzer, M.; Kockmann, N. Microreactor technology and continuous processes in the fine chemical and pharmaceutical industry: Is the revolution underway? Org. Process Res. Dev. 2008, 12 (5), 905-910.

(25) Roberge, D. M.; Ducry, L.; Bieler, N.; Cretton, P.; Zimmermann, B. Microreactor technology: A revolution for the fine chemical and pharmaceutical industries? Chem. Eng. Technol. 2005, 28 (3), 318-323.

(26) Muller, G.; Gaupp, T.; Wahl, F.; Wille, G. Continuous chemistry in microreaction systems for practical use. Chimia 2006, 60 (9), 618-622.

(27) Ehrfeld, W.; Hessel, V.; Löwe, H. Microreactors; Wiley-VCH Verlag GmbH: Weinheim, 2000.

(28) Hessel, V.; Löwe, H.; Müller, A.; Kolb, G. Chemical micro process engineering; Wiley-VCH Verlag GmbH \& Co. KGaA: Weinheim, 2005.

(29) Kockmann, N. Transport phenomena in micro process enginnering, Heat and mass transfer ed.; Mewes, D., Mayinger, F., Eds.; Springer-Verlag: Berlin Heidelberg, 2008.

(30) Kolb, G.; Hessel, V. Micro-structured reactors for gas phase reactions. Chem. Eng. J. 2004, 98 (1-2), 1-38.

(31) Jähnisch, K.; Hessel, V.; Löwe, H.; Baerns, M. Chemistry in Microstructured Reactors. Angew. Chem.-Int. Ed. 2004, 43 (4), 406-446.

(32) Kiwi-Minsker, L.; Renken, A. Microstructured reactors for catalytic reactions. Catal. Today 2005, 110 (1-2), 2-14. 
(33) Hessel, V.; Angeli, P.; Gavriilidis, A.; Löwe, H. Gas-liquid and gas-liquid-solid microstructured reactors: Contacting principles and applications. Ind. Eng. Chem. Res. 2005, 44 (25), 9750-9769.

(34) Warmington, A.; Challenger, S. Microreactor could play a vital role in transitioning fine chemicals from batch process to continuous. Special. Chem. Mag. 2008, 40-41.

(35) Hessel, V., Schouten, J. C., Renken, A., Yoshida, J.-I., Eds. Handbook of Micro Reactors: Fundamentals, Operations and Catalysts; WILEY-VCH Verlag GmbH \& Co. KGaA: Weinheim, Germany, 2009.

(36) Sharma, M. M.; Nanda, A. K. Extraction with second order reaction. Trans. Inst. Chem. Eng. Chem. Eng. 1968, 462, T44.

(37) Ulbrecht, J. J., Patterson, G. K., Eds. Mixing of Liquids By Mechanical Agitation; Gordon and Breach: New York, 1985.

(38) Kantarci, N.; Borak, F.; Ulgen, K. O. Bubble column reactors. Process Biochem. 2005, 40 (7), 2263-2283.

(39) Lo, Y. M.; Hsu, C. H.; Yang, S. T.; Min, D. B. Oxygen transfer characteristics of a centrifugal, packed-bed reactor during viscous xanthan fermentation. Bioprocess. Biosyst. Eng. 2001, 24 (3), 187-193.

(40) Versteeg, G. F.; van Swaaij, W. P. M. Gas-liquid centrifugal reactor. A novel type of gas-liquid contractor; EFCE Publication Series; European Federation of Chemical Engineering,1987; pp B139-B154.

(41) Kolev, N. Packed bed columns: for absorption, desorption, rectification and direct heat transfer; Elsevier: Amsterdam, 2006.

(42) Sie, S. T.; Krishna, R. Process development and scale-up-III: Scaleup and scaledown of trickle bed processes. Rev. Chem. Eng. 1998, 14, $203-$ 251

(43) Alvare, J.; Al-Dahhan, M. H. Gas holdup in trayed bubble column reactors. Ind. Eng. Chem. Res. 2006, 45 (9), 3320-3326.

(44) Meikap, B. C.; Kundu, G.; Biswas, M. N. Mass transfer characteristics of a counter current multi-stage bubble column scrubber. J. Chem. Eng. Jpn. 2004, 37 (10), 1185-1193.

(45) Krishna, R.; Ellenberger, J. Improving gas-liquid mass transfer in bubble columns by applying low-frequency vibrations. Chem. Eng. Technol. 2002, 25 (2), 159-162

(46) Concordia, J. J. Batch catalytic gas/liquid reactors. Types and performance characteristics. Chem. Eng. Prog. 1990, 86 (3), 50-54.

(47) Greenwood, T. S. Loop reactors for catalytic hydrogenation. Chem. Ind. (London) 1986, 3, 94-98.

(48) Poormahdian, S.; Bataille, P. Emulsion copolymerization in a tubular reactor. J. Appl. Polym. Sci. 2000, 75 (6), 833-842.

(49) Asua, J. M., Ed. Polymer reaction engineering; Blackwell Publishing, 2007.

(50) Talens, F. I.; Gutiérrez, J. M.; Mans, C. An improved falling-film reactor for viscous liquids. J. Am. Oil Chem. Soc. 1996, 73 (7), 857-861.

(51) Thompson, J. C.; He, B. B. Biodiesel production using static mixers. Trans. Asabe 2007, 50 (1), 161-165.

(52) Al-Dahhan, M. H.; Larachi, F.; Dudukovic, M. P.; Laurent, A. HighPressure Trickle-Bed Reactors: A Review. Ind. Eng. Chem. Res. 1997, 36 (8), 3292-3314.

(53) Grünewald, M.; Agar, D. W. Intensification of regenerative heat exchange in chemical reactors using desorptive cooling. Ind. Eng. Chem. Res. 2004, 43 (16), 4773-4779.

(54) Pangarkar, K.; Schildhauer, T. J.; Van Ommen, J. R.; Nijenhuis, J.; Kapteijn, F.; Moulijn, J. A. Structured packings for multiphase catalytic reactors. Ind. Eng. Chem. Res. 2008, 47 (10), 3720-3751.

(55) Shah, Y. T. Gas liquid solid reactor design; McGraw Hill: New York, 1979.

(56) Benz, K.; Jäckel, K. P.; Regenauer, K. J.; Schiewe, J.; Drese, K.; Ehrfeld, W.; Hessel, V.; Löwe, H. Utilization of micromixers for extraction processes. Chem. Eng. Technol. 2001, 24 (1), 11-17.

(57) Robins, I.; Shaw, J.; Miller, B.; Turner, C.; Harper, M. Solute transfer by liquid/liquid exchange without mixing in micro-contactor devices. In Microreaction Technology, 1st International Conference on Microreaction Technology, Springer-Verlag: Berlin, 1997; pp 35-46.

(58) Shaw, J.; Turner, C.; Miller, B.; Robins, I.; Kingston, I.; Harper, M. Characterization of micro-contactors for solute transfer between immiscible liquid and developement of arrays for high throughput. In $2 n d$ International Conference on Microreaction Technology; Topical conference preprints, New Orleans; AIChe, 1998.

(59) TeGrotenhuis, W. E.; Cameron, R. J.; Butcher, M. G.; Martin, P. M.; Wegeng, R. S. Microchannel devices for efficient contacting of liquids in solvent extraction. In Process Miniaturization: 2nd International Conference on Microreaction Technology, New Orleans, AIChE, 1998; pp 329-334.

(60) TeGrotenhuis, W. E.; Cameron, R. J.; Viswanathan, V. V.; Wegeng, R. S. Solvent extraction and gas absorption using microchannel contactors. In Microreactor Technology: 3rd International Conference on Microreaction Technology; Topical Conference Preprints; Springer-Verlag: Berlin, 2000; pp 541-549.
(61) Ehrfeld, W.; Gärtner, C.; Golbig, K.; Hessel, V.; Konrad, R.; Löwe, H.; Richter, T.; Schulz, C. Fabrication of components and systems for chemical and biological microreators. In Microreactor Technology: 1st International Conference on Microreactor Technology; Springer-Verlag: Berlin, 1997; pp 72-90.

(62) Garstecki, P.; Fuerstman, M. J.; Stone, H. A.; Whitesides, G. M. Erratum: Formation of droplets and bubbles in a microfluidic T-junction Scaling and mechanism of break-up (Lab on a Chip-Miniaturisation for Chemistry and Biology (2006) 6 (437) DOI: 10.1039/b510841a). Lab Chip 2006, 6 (5), 693-694.

(63) Gavriilidis, A.; Angeli, P. Mixing and contacting of heterogeneous systems. In Handbook of Micro Reactors: Fundamentals, Operations and Catalysts; Hessel, V., Schouten, J. C., Renken, A., Yoshida, J.-I., Ed.; WileyVch Verlag GmbH \& Co. KGaA: Weinheim, Germany, 2009.

(64) Tice, J. D.; Lyon, A. D.; Ismagilov, R. F. Effects of viscosity on droplet formation and mixing in microfluidic channels. Anal. Chim. Acta 2004, 507 (1), 73-77.

(65) Tice, J. D.; Song, H.; Lyon, A. D.; Ismagilov, R. F. Formation of Droplets and Mixing in Multiphase Microfluidics at Low Values of the Reynolds and the Capillary Numbers. Langmuir 2003, 19 (22), 9127-9133.

(66) Burns, J. R.; Ramshaw, C. Development of a microreactor for chemical production. Chem. Eng. Res. Des. 1999, 77 (A3), 206-211.

(67) Köhler, J. M.; Henkel, T.; Grodrian, A.; Kirner, T.; Roth, M.; Martin, K.; Metze, J. Digital reaction technology by micro segmented flow - components, concepts and applications. Chem. Eng. J. 2004, 101 (1-3), 201-216.

(68) Hessel, V.; Rothstock, S.; Löb, P.; Werner, B.; Schelhaas, K. P. Re-Dispersion microreactor to achieve staged liquid-liquid disperson for use in polycondensation. Presented at the 2007 AICHE Spring National Meeting, Houston, TX, 2007.

(69) Jähnisch, K.; Baerns, M.; Hessel, V.; Ehrfeld, W.; Haverkamp, V.; Löwe, H.; Wille, C.; Guber, A. Direct fluorination of toluene using elemental fluorine in gas/liquid microreactors. J. Fluor. Chem. 2000, 105 (1), 117128.

(70) De Bellefon, C.; Lamouille, T.; Pestre, N.; Bornette, F.; Pennemann, H.; Neumann, F.; Hessel, V. Asymmetric catalytic hydrogenations at microlitre scale in a helicoidal single channel falling film micro-reactor. Catal. Today 2005, 110 (1-2), 179-187.

(71) Wenn, D. A.; Shaw, J. E. A.; Mackenzie, B. A mesh microcontactor for 2-phase reactions. Lab Chip 2003, 3 (3), 180-186.

(72) Kreutzer, M. Hydrodynamics of Taylor flow in capillaries and monolith reactors. PhD Thesis, Delft University of Technology, 2003.

(73) Losey, M. W.; Schmidt, M. A.; Jensen, K. F. Microfabricated multiphase packed-bed reactors: Characterization of mass transfer and reactions. Ind. Eng. Chem. Res. 2001, 40 (12), 2555-2562.

(74) Kashid, M. N.; Agar, D. W.; Renken, A.; Kiwi-Minsker, L. Heterogeneous multiphase reactions. In Handbook of Micro Reactors: Fundamentals, Operations and Catalysts; Hessel, V.; Schouten, J. C.; Renken, A.; Yoshida, J.-I, Eds.; Wiley-Vch Verlag GmbH \& Co. KGaA: Weinheim, Germany, 2009.

(75) Bercic, G.; Pintar, A. The role of gas bubbles and liquid slug lengths on mass transport in the Taylor flow through capillaries. Chem. Eng. Sci. 1997, 52 (21-22), 3709-3719.

(76) van Baten, J. M.; Krishna, R. CFD simulations of mass transfer from Taylor bubbles rising in circular capillaries. Chem. Eng. Sci. 2004, 59 (12), 2535-2545.

(77) Pohorecki, R. Effectiveness of interfacial area for mass transfer in two-phase flow in microreactors. Chem. Eng. Sci. 2007, 62 (22), 64956498.

(78) Chambers, R. D.; Hutchinson, J.; Sandford, G. Recent studies at Durham on direct fluorination. J. Fluor. Chem. 1999, 100 (1-2), 63-73.

(79) Chambers, R. D.; Rolling, D.; Spink, R. C. H.; Sandford, G. Elemental fluorine Part 13: Gas-liquid thin film microreactors for selective direct fluorination. Lab Chip-Minituar. Chem. Biol. 2001, 1 (2), 132-137.

(80) Chambers, R. D.; Greenhall, M. P.; Hutchinson, J. Direct fluorination of 1,3-dicarbonyl compounds. Tetrahedron 1996, 52 (1), 1-8.

(81) Chambers, R. D.; Hutchinson, J.; Sparrowhawk, M. E.; Sandford, G.; Moilliet, J. S.; Thomson, J. Elemental fluorine Part 12. Fluorination of 1,4-disubstituted aromatic compounds. J. Fluorine Chem. 2000, 102 (12), 169-173.

(82) Chambers, R. D.; Parsons, M.; Sandford, G.; Skinner, C. J.; Atherton, M. J.; Moilliet, J. S. Elemental fluorine. Part 10.1 Selective fluorination of pyridine, quinoline and quinoxaline derivatives with fluorineiodine mixtures. J. Chem. Soc.-Perkin Trans. 1 1999, (7), 803-810.

(83) Wehle, D.; Dejmek, M.; Rosenthal, J.; Ernst, H.; Kampmann, D.; Trautschold, S.; Pechatschek, R. Chlorinated organic compounds production. WO200210094-A; DE10036603-A1; WO200210094-A1. 
(84) Ehrich, H.; Linke, D.; Morgenschweis, K.; Baerns, M.; Jähnisch, $\mathrm{K}$. Application of microstructured reactor technology for the photochemical chlorination of alkylaromatics. Chimia 2002, 56 (11), 647-653.

(85) Antes, J.; Tuercke, T.; Marioth, E.; Lechner, F.; Scholz, M.; Schnürer, F.; Krause, H. H.; Löbbecke, S. In Microreaction TechnologyIMRET 5: 5th International Conference on Microreaction Technology; Springer: Berlin, 2001; p 446.

(86) Chambers, R. D.; Holling, D.; Rees, A. J.; Sandford, G. Microreactors for oxidations using fluorine. J. Fluor. Chem. 2003, 119 (1), 81-82.

(87) Müller, A.; Cominos, V.; Hessel, V.; Horn, B.; Schürer, J.; Ziogas, A.; Jähnisch, K.; Hillmann, V.; Großer, V.; Jam, K. A.; Bazzanella, A.; Rinke, G.; Kraut, M. Fluidic bus system for chemical process engineering in the laboratory and for small-scale production. Chem. Eng. J. 2005, 107 (1-3), 205-214.

(88) Abdallah, R.; Meille, V.; Shaw, J.; Wenn, D.; De Bellefon, C. Gasliquid and gas-liquid-solid catalysis in a mesh microreactor. Chem. Commun. 2004, 10 (4), 372-373.

(89) de Mas, N.; Jackman, R. J.; Schmidt, M. A.; Jensen, K. F. Microchemical systems for direct fluorination of aromatics. In Microreaction Technology-IMRET 5: 5th International Conference on Microreaction Technology; Springer: Berlin, 2001; p 60.

(90) Song, H.; Ismagilov, R. F. Millisecond kinetics on a microfluidic chip using nanoliters of reagents. J. Am. Chem. Soc. 2003, 125 (47), 14613 14619.

(91) Burns, J. R.; Ramshaw, C. The intensification of rapid reactions in multiphase systems using slug flow in capillaries. Lab Chip 2001, 1 (1), $10-15$.

(92) Kashid, M. N. Experimental and modelling studies on liquid-liquid slug flow capillary microreactors. Ph.D. thesis, Technical University of Dortmund, 2007.

(93) Dessimoz, A. L.; Cavin, L.; Renken, A.; Kiwi-Minsker, L. Liquidliquid two-phase flow patterns and mass transfer characteristics in rectangular glass microreactors. Chem. Eng. Sci. 2008, 63 (16), 4035-4044.

(94) Antes, J.; Boskovic, D.; Krause, H.; Loebbecke, S.; Lutz, N.; Tuercke, T.; Schweikert, W. Analysis and improvement of strong exothermic nitrations in microreactors. Chem. Eng. Res. Des. 2003, 81 (A7), 760-765.

(95) Smirnova, A.; Mawatari, K.; Hibara, A.; Proskurnin, M. A.; Kitamori, T. Micro-multiphase laminar flows for the extraction and detection of carbaryl derivative. Anal. Chim. Acta 2006, 558 (1-2), 69-74.

(96) Hiki, S.; Tokeshi, M.; Hibara, A.; Kitamori, T. Development of a desktop-sized thermal lens microscope. Bunseki Kagaku 2003, 52 (8), 569574.

(97) Krämer, P. M.; Marco, M. P.; Hammock, B. D. Development of a selective enzyme-linked immunosorbent assay for 1-naphthol - The major metabolite of carbaryl (1-naphthyl N-methylcarbamate). J. Agric. Food Chem. 1994, 42 (4), 934-943.

(98) Jenck, J.; Burille, P. Enk: Innovation, http://www.enki2.com (accessed 2009).

(99) Burns, J. R.; Ramshaw, C. A microreactor for the nitration of benzene and toluene. Chem. Eng. Commun. 2002, 189 (12), 1611-1628.

(100) Dummann, G.; Quittmann, U.; Groschel, L.; Agar, D. W.; Worz, O.; Morgenschweis, K. The capillary-microreactor: a new reactor concept for the intensification of heat and mass transfer in liquid-liquid reactions. Catal. Today 2003, 79 (1-4), 433-439.

(101) Kashid, M. N.; Harshe, Y. M.; Agar, D. W. Liquid-liquid slug flow in a capillary: An alternative to suspended drop or film contactors. Ind. Eng. Chem. Res 2007, 46 (25), 8420-8430.

(102) Doku, G. N.; Haswell, S. J.; McCreedy, T.; Greenway, G. M. Electric field-induced mobilisation of multiphase solution systems based on the nitration of benzene in a micro reactor. Analyst 2001, 126 (1), 14 20.

(103) Alexanderson, V.; Trecek, J. B.; Vanderwaart, C. M. Continuous adiabatic process for the mononitration of benzene. US Patent 4,091,042, 1978.

(104) Guenkel, A. A.; Rae, J. M.; Hauptmann, E. G. Nitration process. US Patent 5,313,009, 1994

(105) http://cbee.oregonstate.edu/research/jovanovic/ (accessed 2003). (106) http://www.clarkson.edu/chemeng/faculty/jachuck.html.

(107) Dorado, M. P.; Ballesteros, E.; Lopez, F. J.; Mittelbach, M. Optimization of alkali-catalyzed transesterification of Brassica Carinata oil for biodiesel production. Energy Fuels 2004, 18 (1), 77-83.

(108) Darnoko, D.; Cheryan, M. Kinetics of palm oil transesterification in a batch reactor. J. Am. Oil Chem. Soc. 2000, 77 (12), 1263-1267.

(109) Noureddini, H.; Medikonduru, V. Glycerolysis of fats and methyl esters. J. Am. Oil Chem. Soc. 1997, 74 (4), 419-425.

(110) Xu, Y.; Du, W.; Liu, D.; Zeng, J. A novel enzymatic route for biodiesel production from renewable oils in a solvent-free medium. Biotechnol. Lett. 2003, 25 (15), 1239-1241.
(111) Darnoko, D.; Cheryan, M. Continuous production of palm methyl esters. J. Am. Oil Chem. Soc. 2000, 77 (12), 1269-1272.

(112) Noureddini, H.; Harkey, D.; Medikonduru, V. A continuous process for the conversion of vegetable oils into methyl esters of fatty acids. J. Am. Oil Chem. Soc. 1998, 75 (12), 1775-1783.

(113) Hsu, A. F.; Jones, K. C.; Foglia, T. A.; Marmer, W. N. Continuous production of ethyl esters of grease using an immobilized lipase. J. Am. Oil Chem. Soc. 2004, 81 (8), 749-752.

(114) Simonsen, J. L. The terpenes; Cambridge University Press: New York, 1931; Vol. I.

(115) Hertel, O.; Kiefer, H.; Arnold, L. Preparation of ionones. US Patent 4,565,894, 1986.

(116) Rheude, U.; Horcher, U.; Weller, D.; Stroezel, M. Process for preparing ionones. US Patent 6,140,542, 2000.

(117) Royals, E. E. Cyclisation of pseudoionone by acidic reagents. Ind. Eng. Chem. Res. 1946, 38 (5), 546-548.

(118) Löwe, H.; Ehrfeld, W. State-of-the-art in microreaction technology: concepts, manufacturing and applications. Electrochim. Acta 1999, 44 (21), 3679-3689.

(119) Wörz, O.; Jäckel, K. P.; Richter, T.; Wolf, A. Microreactors, a new efficient tool for optimum reactor design. Chem. Eng. Sci. 2001, 56 (3), 1029-1033.

(120) Wörz, O.; Jäckel, K. P.; Richter, T.; Wolf, A. Microreactors, a new efficient tool for optimum reactor design. In 2nd International Conference on Microreaction Technology, New Orleans, 1998; 183.

(121) Ahmed, B.; Barrow, D.; Wirth, T. Enhancement of reaction rates by segmented fluid flow in capillary scale reactors. Adv. Synth. Catal. 2006, 348 (9), 1043-1048.

(122) Ahmed-Omer, B.; Barrow, D.; Wirth, T. Effect of segmented fluid flow, sonication and phase transfer catalysis on biphasic reactions in capillary microreactors. Chem. Eng. J. 2007, 135 (SUPPL. 1), S280-S283.

(123) Maruyama, T.; Uchida, J. I.; Ohkawa, T.; Futami, T.; Katayama, K.; Nishizawa, K. I.; Sotowa, K. I.; Kubota, F.; Kamiya, N.; Goto, M. Enzymatic degradation of p-chlorophenol in a two-phase flow microchannel system. Lab Chip-Miniatur. Chem. Biol. 2003, 3 (4), 308-312.

(124) Sasson, Y.; Neumann, R., Eds. Handbook of phase transfer catalysis; Blackie academics and professionals: London, 1997.

(125) Fiamegos, Y. C.; Stalikas, C. D. Phase-transfer catalysis in analytical chemistry. Anal. Chim. Acta 2005, 550 (1-2), 1-12.

(126) Satrio, J. A. B.; Doraiswamy, L. K. Phase-transfer catalysis: A new rigorous mechanistic model for liquid-liquid systems. Chem. Eng. Sci. 2002, 57 (8), 1355-1377.

(127) Ueno, M.; Hisamoto, H.; Kitamori, T.; Kobayashi, S. Phasetransfer alkylation reactions using microreactors. Chem. Commun. 2003, 8, 936-937.

(128) Kiparissides, C. Polymerization reactor modeling: A review of recent developments and future directions. Chem. Eng. Sci. 1996, 51 (10), $1637-1659$.

(129) Nakashima, T.; Shimizu, M.; Kukizaki, M. Membrane emulsification by microporous glass. Key Eng. Mater. 1991, 61-62, 513-516.

(130) Kawakatsu, T.; Kikuchi, Y.; Nakajima, M. Regular-sized cell creation in microchannel emulsification by visual microprocessing method. J. Am. Oil Chem. Soc. 1997, 74 (3), 317-321.

(131) Umbanhowar, P. B.; Prasad, V.; Weitz, D. A. Monodisperse emulsion generation via drop break off in a coflowing stream. Langmuir 2000, 16 (2), 347-351.

(132) Thorsen, T.; Roberts, R. W.; Arnold, F. H.; Quake, S. R. Dynamic pattern formation in a vesicle-generating microfluidic device. Phys. Rev. Lett. 2001, 86 (18), 4163-4166.

(133) Sugiura, S.; Nakajima, M.; Iwamoto, S.; Seki, M. Interfacial tension driven monodispersed droplet formation from microfabricated channel array. Langmuir 2001, 17 (18), 5562-5566.

(134) Sugiura, S.; Nakajima, M.; Itou, H.; Seki, M. Synthesis of polymeric microspheres with narrow size distributions employing microchannel emulsification. Macromol. Rapid Commun. 2001, 22 (10), 773778.

(135) Kobayashi, I.; Nakajima, M.; Chun, K.; Kikuchi, Y.; Fujita, H. Silicon array of elongated through-holes for monodisperse emulsion droplets. AIChE J. 2002, 48 (8), 1639-1644.

(136) Nisisako, T.; Torii, T.; Higuchi, T. Droplet formation in a microchannel network. Lab Chip-Miniatur. Chem. Biol. 2002, 2 (1), 2426.

(137) Okushima, S.; Nisisako, T.; Torii, T.; Higuchi, T. Controlled production of monodisperse double emulsions by two-step droplet breakup in microfluidic devices. Langmuir 2004, 20 (23), 9905-9908.

(138) Ikkai, F.; Iwamoto, S.; Adachi, E.; Nakajima, M. New method of producing mono-sized polymer gel particles using microchannel emulsification and UV irradiation. Colloid Polym. Sci. 2005, 283 (10), 1149-1153. 
(139) Seo, M.; Nie, Z.; Xu, S.; Mok, M.; Lewis, P. C.; Graham, R.; Kumacheva, E. Continuous microfluidic reactors for polymer particles. Langmuir 2005, 21 (25), 11614-11622.

(140) Bouquey, M.; Serra, C.; Berton, N.; Prat, L.; Hadziioannou, G. Microfluidic synthesis and assembly of reactive polymer beads to form new structured polymer materials. Chem. Eng. J. 2007, 135 (SUPPL. 1), S93S98.

(141) Hönicke, D.; Wiessmeier, G. Microsystem Technology for Chemical and Biological Microreactors. DECHEMA Monogr. 1996, 132, 93-107.

(142) Wiessmeier, G.; Honicke, D. Microfabricated components for heterogeneously catalysed reactions. J. Micromech. Microeng. 1996, 6 (2), 285-289.

(143) Wiessmeier, D.; Schubert, K.; Hönicke, D. Monolithic microstructure reactors possessing regular mesopore systems for the successful performance of heterogeneously catalyzed reactions. IMRET1, 1st International Conference on Microreaction Technology; Springer: Berlin, 1997; pp 20-26.

(144) Haas-Santo, K.; Gorke, O.; Pfeifer, P.; Schubert, K. Catalyst coatings for microstructure reactors. Chimia 2002, 56 (11), 605-610.

(145) Ganley, J. C.; Riechmann, K. L.; Seebauer, E. G.; Masel, R. I. Porous anodic alumina optimized as a catalyst support for microreactors. J. Catal. 2004, 227 (1), 26-32.

(146) Brinker, C. J.; Scherer, G. W. Sol-Gel Science; Academic Press: New York, 1990.

(147) Gonzalez, R. D.; Lopez, T.; Gomez, R. Sol-gel preparation of supported metal catalysts. Catal. Today 1997, 35 (3), 293-317.

(148) Reuse, P. Production d'hydrogéne dans un réacteur microstructuré. Couplage themque entre le steam reforming et l'oxydation totale du méthanol. Ph.D. Thesis, EPFL Lausanne, 2003.

(149) Rouge, A. Periodic operation of a microreactor for heterogeneously catalyzed reactions: the dehydration of isopropanol. Thesis, EPFL Lausanne, 2001.

(150) Pfeifer, P.; Schubert, K.; Emig, G. Preparation of copper catalyst washcoats for methanol steam reforming in microchannels based on nanoparticles. Appl. Catal., A 2005, 286 (2), 175-185.

(151) Coronas, J.; Santamaria, J. The use of zeolite films in small-scale and micro-scale applications. Chem. Eng. Sci. 2004, 59 (22-23), 48794885 .

(152) Hiemer, U.; Klemm, E.; Scheffler, F.; Selvam, T.; Schwieger, W.; Emig, G. Microcreation engineering studies of the hydroxylation of benzene with nitrous oxide. Chem. Eng. J. 2004, 101 (1-3), 17-22.

(153) Rebrov, E. V.; Seijger, G. B. F.; Calis, H. P. A.; de Croon, M.; van den Bleek, C. M.; Schouten, J. C. The preparation of highly ordered single layer ZSM-5 coating on prefabricated stainless steel microchannels. Appl. Catal., A 2001, 206 (1), 125-143.

(154) Louis, B.; Kiwi-Minsker, L.; Reuse, P.; Renken, A. ZSM-5 coatings on stainless steel grids in one-step benzene hydroxylation to phenol by $\mathrm{N} 2 \mathrm{O}$ : Reaction kinetics study. Ind. Eng. Chem. Res. 2001, 40 (6), 1454-1459.

(155) Louis, B.; Reuse, P.; Kiwi-Minsker, L.; Renken, A. Synthesis of ZSM-5 coatings on stainless steel grids and their catalytic performance for partial oxidation of benzene by $\mathrm{N}_{2} \mathrm{O}$. Appl. Catal. A: Gen. 2001, 210 (12), 103-109.
(156) Janicke, M. T.; Kestenbaum, H.; Hagendorf, U.; Schuth, F.; Fichtner, M.; Schubert, K. The controlled oxidation of hydrogen from an explosive mixture of gases using a microstructured reactor/heat exchanger and $\mathrm{Pt} / \mathrm{Al}_{2} \mathrm{O}_{3}$ catalyst. J. Catal. 2000, 191 (2), 282-293.

(157) Thybo, S.; Jensen, S.; Johansen, J.; Johannessen, T.; Hansen, O.; Quaade, U. J. Flame spray deposition of porous catalysts on surfaces and in microsystems. J. Catal. 2004, 223 (2), 271-277.

(158) Schimpf, S.; Bron, A.; Claus, P. Carbon-coated microstructured reactors for heterogeneously catalyzed gas phase reactions: influence of coating procedure on catalytic activity and selectivity. Chem. Eng. J. 2004, $101(1-3), 11-16$.

(159) Tribolet, P.; Kiwi-Minsker, L. Palladium on carbon nanofibers grown on metallic filters as novel structured catalyst. Catal. Today $\mathbf{2 0 0 5}$, 105 (3-4), 337-343.

(160) Tribolet, P.; Kiwi-Minsker, L. Carbon nanofibers grown on metallic filters as novel catalytic materials. Catal. Today 2005, 102, 1522.

(161) Losey, M. W.; Jackman, R. J.; Firebaugh, S. L.; Schmidt, M. A.; Jensen, K. F. Design and fabrication of microfluidic devices for multiphase mixing and reaction. J. Microelectromech. S. 2002, 11 (6), 709-717.

(162) Losey, M. W.; Schmnidt, M. A.; Jensen, K. F. A micro packed bed for chemical synthesis. In International conference on microreaction technology (IMRET 3); Springer-verlag: Frankfurt, Germany, 2000; pp 277286.

(163) Yeong, K. K.; Gavriilidis, A.; Zapf, R.; Hessel, V. Catalyst preparation and deactivation issues for nitrobenzene hydrogenation in a microstructured falling film reactor. Catal. Today 2003, 81 (4), 641-651.

(164) Herskowitz, M.; Carbonell, R. G.; Smith, J. M. Effectiveness factors and mass transfer in trickle-bed reactors. AIChE J. 1979, 25 (2), 272-283.

(165) Födisch, R.; Hönicke, D.; Xu, Y.; Platzer, B. Liquid phase hydrogenation of $p$-nitrotoluene in microchannel reactors. In International Conference on Microreaction Technology (IMRET 5), Strasbourge, France; Springer-Verlag: Berlin 2001; pp 470-478.

(166) Reschetilowski, W.; Honicke, D. Heterogeneously catalyzed liquidphase hydrogenation of nitro-aromatics using microchannel reactors. DGMK Tagungsber. 1999, (9903), 231-238.

(167) Wenn, D. A.; Shaw, J. E. A.; Mackenzie, B. A mesh microreactor for 2-phase reactions. Lab Chip-Miniatur. Chem. Biol. 2003, 3 (3), 180.

(168) Jensen, K. F. Microchemical systems module, Massachusetts Institute of Technology, http://web.mit.edu/10.491/.

Received for review November 25, 2008 Revised manuscript received April 5, 2009 Accepted April 14, 2009

IE8017912 